\title{
Kinetics of gene expression and bone remodelling in the clinical phase of collagen-induced arthritis
}

\author{
Katja CM Denninger ${ }^{1,2^{*}}$, Thomas Litman², Troels Marstrand ${ }^{2}$, Kristian Moller $^{2}$, Lars Svensson ${ }^{2}$, Tord Labuda ${ }^{2}$ \\ and Åsa Andersson ${ }^{1}$
}

\begin{abstract}
Introduction: Pathological bone changes differ considerably between inflammatory arthritic diseases and most studies have focused on bone erosion. Collagen-induced arthritis (CIA) is a model for rheumatoid arthritis, which, in addition to bone erosion, demonstrates bone formation at the time of clinical manifestations. The objective of this study was to use this model to characterise the histological and molecular changes in bone remodelling, and relate these to the clinical disease development.
\end{abstract}

Methods: A histological and gene expression profiling time-course study on bone remodelling in CIA was linked to onset of clinical symptoms. Global gene expression was studied with a gene chip array system.

Results: The main histopathological changes in bone structure and inflammation occurred during the first two weeks following the onset of clinical symptoms in the joint. Hereafter, the inflammation declined and remodelling of formed bone dominated.

Global gene expression profiling showed simultaneous upregulation of genes related to bone changes and inflammation in week 0 to 2 after onset of clinical disease. Furthermore, we observed time-dependent expression of genes involved in early and late osteoblast differentiation and function, which mirrored the histopathological bone changes. The differentially expressed genes belong to the bone morphogenetic pathway (BMP) and, in addition, include the osteoblast markers integrin-binding sialoprotein (Ibsp), bone gamma-carboxyglutamate protein (Bglap1), and secreted phosphoprotein 1 (Spp 1). Pregnancy-associated protein A (Pappa) and periostin (Postn), differentially expressed in the early disease phase, are proposed to participate in bone formation, and we suggest that they play a role in early bone formation in the CIA model. Comparison to human genome-wide association studies (GWAS) revealed differential expression of several genes associated with human arthritis.

Conclusions: In the CIA model, bone formation in the joint starts shortly after onset of clinical symptoms, which results in bony fusion within one to two weeks. This makes it a candidate model for investigating the relationship between inflammation and bone formation in inflammatory arthritis.

\section{Introduction}

Inflammatory arthritis is characterised by joint destruction, often resulting in severe distortion of the joint architecture, and leading to impaired function of the joints. The balance between anabolic and catabolic bone remodelling, however, differs between the inflammatory arthritic diseases rheumatoid arthritis (RA), psoriatic arthritis

\footnotetext{
* Correspondence: katjadenninger@gmail.com

${ }^{1}$ Department of Drug Design and Pharmacology, Faculty of Health and

Medical Sciences, University of Copenhagen, Universitetsparken 2, Copenhagen $\varnothing$ DK-2100, Denmark

2Disease Pharmacology/Molecular Biomedicine, LEO Pharma A/S, Industriparken 55, Ballerup DK-2750, Denmark
}

(PsA), and ankylosing spondylitis (AS). While RA primarily is an erosive disease, bone erosion and bone formation co-exist in patients with PsA and AS [1]. Why the bone responds differently to an inflammatory insult is not clarified, but may be important in directing future treatment strategies.

Collagen-induced arthritis (CIA) is a model for RA both due to its construct validity, including autoimmune reaction to collagen type II and MHC class II dependency, and due to its face validity, that is severe bone destruction. Moreover, disease development ends in bony fusion (ankylosis) of the destroyed joints, which could 
make it a relevant model for bone-forming inflammatory arthritic diseases.

Bone formation in CIA has been described as starting two to four weeks after onset of arthritis, but mainly playing a role in the healing state two to three months after onset [2]. However, in a kinetic study of new bone formation in CIA and adjuvant-induced arthritis (AIA) in rat, periosteal proliferation was reported as early as day 3 (CIA) and day 5 (AIA) after onset of arthritis, and new bone formation peaked at day 27 in both models [3].

Bone formation may occur directly within the mesenchyme (intramembranous) or via a cartilage scaffold (endochondral ossification). In both processes, the extracellular matrix (ECM) is mineralised. In particular two pathways have been implicated in osteoblast differentiation and bone formation: the bone morphogenetic protein (BMP) signalling pathway, of which several proteins induce ectopic bone formation [4], and the wingless-type (WNT) signalling pathway [5].

With the aim to understand the molecular mechanisms linking inflammation with new bone formation, the present study was initiated to histologically characterise bone remodelling in the CIA model throughout the disease course, and to relate this to gene expression. To minimise variation between the data and enable correlation to clinical duration of arthritis, we used tarsal joints with a clinical score of 3 . By grouping the tarsal joints according to onset and duration of symptoms, we show that the process of bone formation runs in parallel with the local inflammatory process in the joint, with a concomitant differential expression of genes involved in bone remodelling.

\section{Methods}

\section{Animal model}

Arthritis was induced in male DBA/1JBom mice by intradermal injection of $100 \mu \mathrm{l}$ chicken collagen type II (CII) $(2 \mathrm{mg} / \mathrm{ml})$ (Sigma-Aldrich, St Louis, MO, USA) in complete Freund's adjuvant (CFA) $(0.5 \mathrm{mg} / \mathrm{ml})$ (SigmaAldrich) on day 1 and boosted on day 21 with CII in incomplete Freund's adjuvant (IFA) (Sigma-Aldrich). The control group received CFA and IFA without collagen, respectively. The mice were scored for onset, severity and duration of arthritis in the tarsal joints. Severity in this joint was scored from 0 (no erythema or swelling) to 3 (severe erythema and swelling). Tarsal joints were collected for histology and gene expression analysis. The mice were, in addition, assigned a total score for all four paws (with a theoretical maximum of 24 points for all paws). This additional scoring system was used to judge when the animals should be euthanized as required by Danish legislation (score exceeding 10 points). The mice were housed under standard conditions, and provided pellets and water ad libitum. The Danish Ethics Authorities
'The Animal Experiments Inspectorate' approved the studies (permit number: 2008/561 - 1532).

\section{Histology}

Fifty-two tarsal joints were collected for histology. The tarsal joints were divided into groups according to duration of arthritis in the joint: day 0 to 3 , day 4 to 7 , week 1 to $2,>2$ weeks, and $>2$ weeks with declining inflammation ('declined'). In the group 'declined' the joints previously had a clinical score of 3 for minimum two weeks, after which the clinical score had declined $>1$ score at the time the joint was sampled. For all other joints, the clinical score was 3 at the sampling time. For number of joints per time-point, see Table S2A in Additional file 1. The joints were fixed in formalin and decalcified in 10\% Na-EDTA for two to three weeks.

Haematoxylin and eosin-stained sections were assigned a score for bone erosion, bone formation, synovitis, tendinitis, and peritendinitis. Bone remodelling was judged by the degree of modulation of joint structure, presence of osteoclasts (OCs) and osteoblasts (OBs), and formation of cartilage and woven bone (Figure S1 in Additional file 2). Synovitis, tendinitis and peritendinitis were scored by the degree of infiltrating cells and fibrosis. All features were scored from 0 (no pathologic changes) to 4 (severe pathologic changes).

\section{RNA extraction and microarray analysis}

Three tarsal joints were sampled per group (twelve joints in total). For the group 'More than two weeks, with declined inflammation' the joints had had a clinical score of 3 for minimum two weeks, after which the clinical score had declined $>1$ score at the time for sampling. For all other joints, the clinical score was 3 when sampled (Table S2B in Additional file 1). The twelve joints were compared to three joints from non-immunised control animals. The joints were processed and analysed separately (unpooled). Skin, visible muscle tissue and fur were removed and tarsal joints collected by transverse sectioning of the metatarsus bones and the tibia/fibula under the fur border. This procedure ensured that all joints in the tarsus were included in each sample. Except for the skin and visible muscle, all other soft tissues were included in the sample. The joints were subsequently snap-frozen in liquid $\mathrm{N}_{2}$ and stored at $-80^{\circ} \mathrm{C}$. RNA was extracted using the mirVana ${ }^{\text {"w }}$ miRNA isolation kit (Ambion, Exiqon A/S, Vedbæk Denmark), amplified and labelled using the Pico amplification kit (Nugen Technologies, San Carlos, CA, USA), according to the manufacturers' instructions, followed by hybridisation to Mouse Gene 1.0ST microarrays (Affymetrix, Santa Clara, CA, USA).

The quality of the RNA was evaluated using the RNA integrity number (RIN), and only samples with RIN $>8.3$ were included for further analysis. 
Arrays were normalized using RMA background correction and quantile normalisation in R v.2.15 (Additional file 3). Significance of differentially expressed genes was assessed by analysis of variance (ANOVA), and adjusted for multiple testing by estimating false discovery rates (FDR). Data visualisation was performed in Qlucore Omics Explorer v.2.2 (Qlucore AB, Lund, Sweden). The expression data are deposited in Gene Expression Omnibus [6]; accession number: Series record GSE61140).

Functional analysis and network representation of differentially expressed genes was performed in Ingenuity Pathway Analysis (IPA, Ingenuity ${ }^{\text {m }}$ Systems). Gene expression levels are indicated in the IPA networks as red (upregulated) or green (downregulated) in comparison to non-induced controls.

The differentially regulated genes assigned to Bio Functions of bone and skeleton, were used to compile a comprehensive list of genes potentially involved in bone remodelling in the CIA model.

\section{Quantitative PCR}

For qPCR analysis of Bmp1, RNA (90 ng per reaction) was reverse transcribed to cDNA using the High Capacity cDNA Reverse Transcription kit (Applied Biosystems, Carlsbad, CA, USA). qPCR was performed with TaqMan Universal PCR Mastermix (Applied Biosystems, USA) and primer-assays Bmp1 Mm00802225_m1 and Gapdh Mm99999915_g1 (Applied Biosystems, USA). PCR was initiated at $50^{\circ} \mathrm{C}$ for 2 minutes and $95^{\circ} \mathrm{C}$ for 10 minutes, and the cycling conditions were $95^{\circ} \mathrm{C}$ for 15 seconds and $60^{\circ} \mathrm{C}$ for 1 minute (40 cycles). For the remaining 14 genes (Table S4 in Additional file 4), qPCR analysis was performed by AROS Applied Biotechnology A/S (Aarhus, Denmark). cDNA was prepared from 100 ng RNA/sample using the High Capacity cRNA Reverse Transcription kit (Applied Biosystems, USA) and the qPCR reaction was performed with TaqMan " Universal PCR Master Mix (Applied Biosystems, USA). Assay IDs for the specific primer/probe sets (Life Technologies, Carlsbad, CA, USA) are listed in Table S4 in Additional file 4. Samples were analysed as triplicates and normalized by subtraction of the sample mean $\mathrm{Ct}$ value from that of the mean $\mathrm{Ct}$ value of the housekeeping gene Gapdh.

\section{Statistics}

Histological scoring results were assessed using KruskallWallis test followed by a Dunn's multiple comparisons test. qPCR results were analysed by ANOVA, followed by Bonferroni's multiple comparison test, and compared by linear regression to array results. The significance of the correlation coefficients was tested using Student's $t$-distribution. All statistical analyses were performed in GraphPad Prism v.5 (GraphPad Software, San Diego,
CA, USA), with the statistical unit being one joint from each animal included.

\section{Results}

Development of arthritis and histopathology of CIA from onset to decline of clinical symptoms

After immunization with chicken CII, mean onset of arthritis was observed on day $31 \pm 8.8$. Mean score of arthritis peaked six weeks after boost with a mean score of $4.6 \pm 1.8$. In order to study local arthritis development, onset and severity of arthritis in the tarsal joint was recorded in detail.

For the histological study, a total of 52 tarsal joints were used. Fourteen were sampled between day 0 and 4 , ten between day 4 and 7 , eleven between week 1 and 2, and seventeen after week 2 of clinical inflammation onset. After week 2, twelve samples showed declining clinical symptoms. Little variation in the appearance of synovitis, peritendinitis, and bone remodelling was noted within the groups. The data are in accordance with a previously published study showing occurrence of bony spur formation early after disease onset [3].

Day 0 to 4 after clinical disease onset: The infiltration of inflammatory cells was equally pronounced when comparing the synovium (mean score $3.8+/-0.4$ ) and the peritendon (mean score $3.9+/-0.3$ ) (Figure 1A). In $10 / 14$ joints, fibroblast activity and fibrosis indicated chronic inflammation, while $4 / 14$ joints had no signs of chronicity. Bone pathology was dominated by erosion (11/14 joints), initiated where the peritendon and synovium are attached to, or in close proximity to the bone, while the articular cartilage remained intact. Bone erosion was severe as judged by the presence of multinucleated osteoclasts (OC) and the extent of structural damage of the cartilage and bone tissue (Figure 1B). However, both $\mathrm{OB}$ proliferation, and collagen deposition, was observed in the periosteum and seemed, from visible staining ability, to have progressed into secretion of osteoid-like matrix in $3 / 14$ joints (Figure $1 \mathrm{C}$ ).

Day 4 to 7 after clinical disease onset: Severe fibrosis and synovitis approaching the articular cartilage, and resulting in erosion of the articular cartilage, was observed (Figure 1D). In areas of less severe inflammation, pronounced $\mathrm{OB}$ activity and onset of endochondral ossification was noted as judged from the appearance of hypertrophic cartilage. Bone erosion (mean score of $3.1+/-1.3$ ) and bone formation $(2.2+/-1.1)$, was observed in $9 / 10$ joints.

Week 1 to 2 after clinical disease onset: Bone erosion (score 2.6+/-1.4) and bone formation (score 2.9+/-1.1) was pronounced and observed in 10/11 joints. Endochondral ossification was dominating (Figure 2A). Ankylosis was noted from day 8 and consisted of an inner layer of remodelled bone, followed by a cartilage layer. 

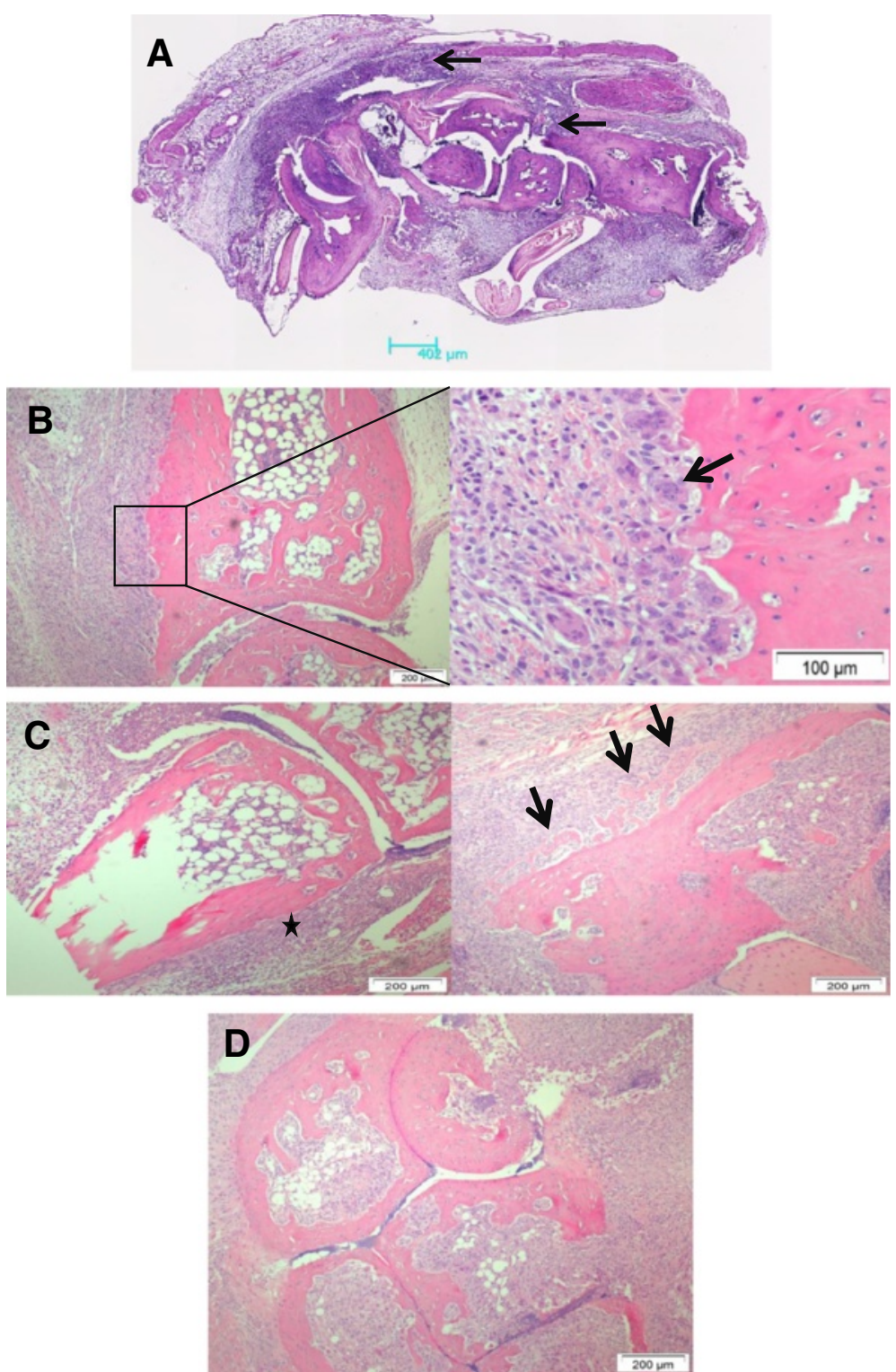

Figure 1 Histopathology of tarsal joints day 0 to 7. A) Day 0 to 4: overview of inflammation in the tarsal joint showing equal severity of inflammation in peripheral tissues and synovium (arrows). (B-C) Day 0 to 4: bone erosion and OC activity (arrow in B, day 3) dominates. Proliferation and collagen deposition takes place (star in C, day 0) in the periosteum and results in osteoid deposition (arrows in C, day 3). (D) Day 4 to 7: the joint architecture is severely distorted (day 7). OC, osteoclast.

The outer lining layer of the bone-forming lesion consisted of mesenchymal cells (Figure 2B). In most joints, inflammation was severe, but gradually disappearing and replaced by severe fibrosis with yet active fibroblast proliferation.

Two weeks after clinical disease onset: The clinical severity of inflammation was declining in most joints, although 5/17 joints still showed severe clinical signs. In the joints with severe clinical arthritis, accumulation of cartilage was still apparent, while in joints with declining clinical symptoms, an increase in what was observed as mineralisation of cartilage and newly formed bone took place, in addition to modification of the newly formed bone by OCs (Figure 2C).

By comparing the development in scores for bone erosion and bone formation, respectively, a significant difference over time was observed with the greatest development in scores of bone formation ( $\mathrm{P}=0.0186$ vs. $P<0.0001)$ (Figure 2D).

\section{Gene expression in joints from mice with CIA normalises} after two weeks of inflammation

Having examined the bone remodelling after clinical onset of arthritis histologically, we aimed at describing the 

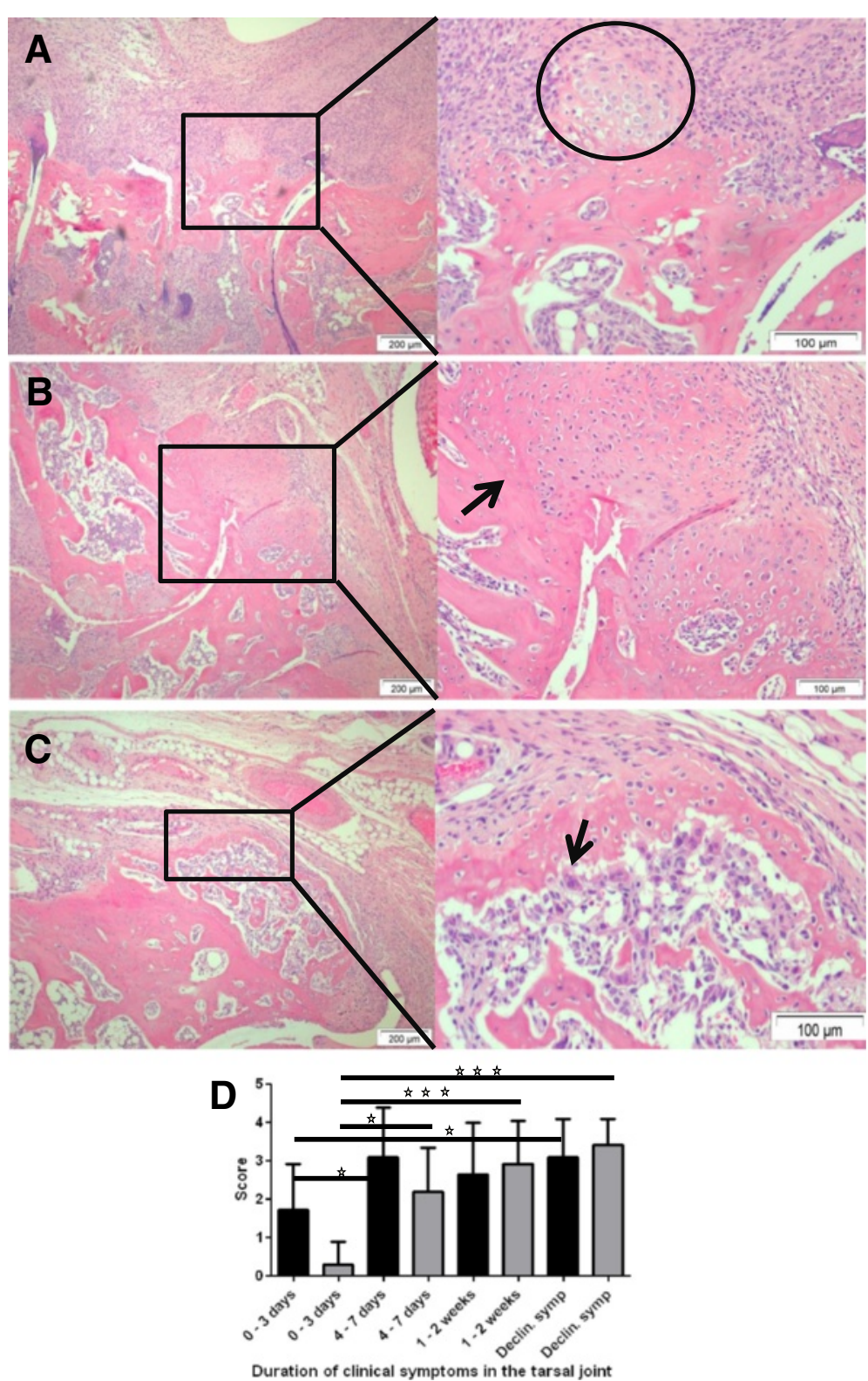

Figure 2 Histopathology of tarsal joints from day $\mathbf{8}$ and until decline of symptoms. (A) Appearance of cartilage (encircled) marks the onset of endochondral ossification (day 8). (B) Ankylosis has progressed from being fibrous to consist of cartilage and osteoid (day 10), with osteoid closest to the original bone (arrow). (C) Declining disease phase: bone formation is remodelled with OC activity observed in some animals (arrow). (D) Histological scores of bone erosion (black bars) and bone formation (grey bars) over time (mean $+/-$ standard deviation (SD)). Statistics from the comparisons of individual groups is indicated by lines above the bars (Dunn's multiple comparison test, ${ }^{*} P<0.05$, ${ }^{* *} P<0.01$, ***P $<0.001)$. OC, osteoclast.

time course of bone remodelling by global gene expression profiling (Figure $3 \mathrm{~A}$ and $\mathrm{B}$ ).

Unsupervised hierarchical clustering grouped the samples into a phase of high transcriptional activity between week 0 and 2, and, subsequently, a period of declining transcriptional activity. One sample from the declining disease phase (decline 10) clustered together with the controls, showing that the gene expression pattern normalised in the late disease phase (Figure 3A). In the first three days, 908 genes displayed a +2 -fold change in the transcriptional level, while 749 genes were differentially expressed in week 1 to 2 ( $>2$ fold change, $P<0.05$ ). The IPA showed that the top biological functions, canonical pathways, and upregulated genes were dominated by genes involved in arthritis and the immune system in general, in connective and skeletal tissue disorders and remodelling, as well as tissue development and function (Table S5A and B in Additional file 5). 


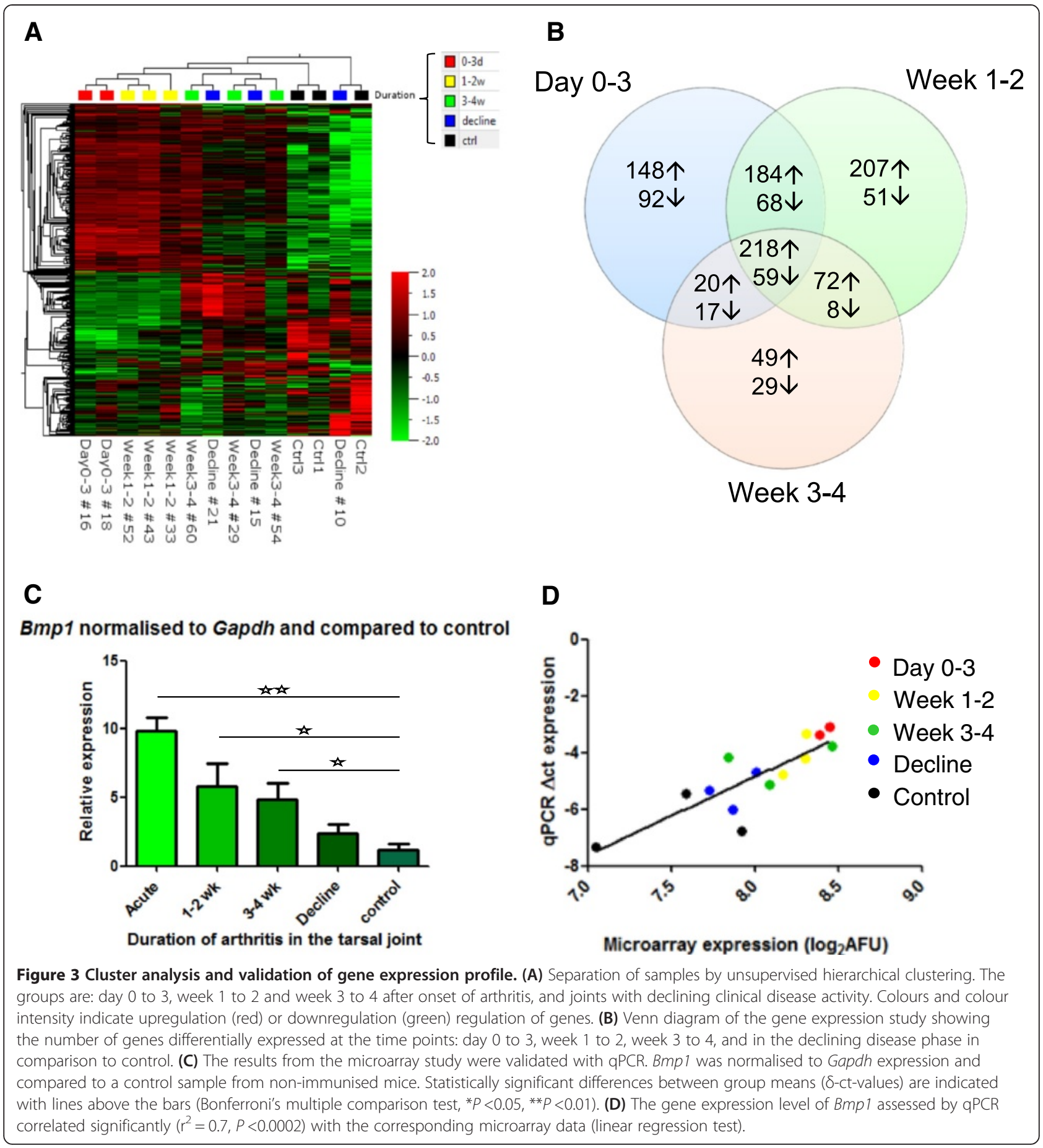

Several potentially disease-relevant genes (Saa3, Timp1, Postn, Ctsk, Mmp3 and Mmp13) demonstrated very high fold changes (between 10.6 and 45.3) (Table 1). Moreover, pregnancy-associated plasma protein A (Pappa) was strongly upregulated when comparing day 0 to 3 with week 1 to 2 (fold change +2.3 ) (Table 2). A muscle- and epidermis-specific gene expression signature was found among the most downregulated genes when comparing day 0 to 3 and control samples (Table 1).

In week 3 to 4 after onset of disease, the number of two-fold differentially expressed genes had decreased to 353 (Figure 3B). The pathway profile changed accordingly, and was dominated by tissue remodelling and developmental pathways, although an inflammatory gene 
Table 1 Highly differentially expressed genes grouped according to function

\begin{tabular}{|c|c|c|c|c|c|c|c|c|}
\hline Gene symbol & $\operatorname{Ctrl}\left(\log _{2} A F U\right)^{a}$ & Day 0 to $3^{b}$ & week 1 to $2^{c}$ & Week 3 to $4^{d}$ & Decline $^{\mathrm{e}}$ & Localisation & Ar vs. $N^{f}$ & Ar vs. $\mathrm{N}^{\mathrm{g}}$ \\
\hline $\mathrm{Saa3}$ & 6.8 & 44.1 & 26.2 & 7.8 & 2.7 & Plasma & 18.0 & 2.0 \\
\hline Mmp3 & 7.2 & 23.1 & 11.9 & 5.2 & 2.9 & Synovium & 10.1 & 5.3 \\
\hline Mmp13 & 7.6 & 13.2 & 17.3 & 8.9 & 4.5 & Synovium & 3.5 & 2.3 \\
\hline Timp1 & 7.5 & 19.4 & 9.3 & 5.3 & 3.4 & Synovium & 1.9 & 3.5 \\
\hline Ctsk & 7.8 & 11.0 & 11.7 & 7.6 & 4.8 & Osteoclasts & 2.8 & 1.7 \\
\hline Atp6rod2 & 6.97 & 9.03 & 7.18 & 5.94 & 3.67 & Endosome & 1.5 & 1.0 \\
\hline Postn & 8.5 & 10.3 & 9.8 & 5.0 & 2.5 & Osteoblasts & 4.5 & 1.0 \\
\hline Krtdap & 7.6 & 0.1 & 0.2 & 4.5 & 14.1 & Skin* & 0.4 & 1.1 \\
\hline Lcela1/1a2 & 8.2 & 0.1 & 0.1 & 2.8 & 7.9 & Skin & NA & 1.0 \\
\hline Lor & 8.4 & 0.1 & 0.2 & 3.7 & 5.4 & Skin* & 0.6 & 1.1 \\
\hline Krt1/2/5/14 & 7.8 & 0.1 & 0.2 & 3.4 & 10.3 & Skin* & 0.8 & 1.0 \\
\hline Mt4 & 7.40 & 0.32 & 0.36 & 4.63 & 19.15 & Epithelia* & 0.8 & 1.0 \\
\hline Myl2 & 10.5 & 0.1 & 0.8 & 1.0 & 1.0 & Muscle & 0.2 & 0.6 \\
\hline Pygm & 10.8 & 0.1 & 0.4 & 0.4 & 0.6 & Muscle & 0.5 & 0.7 \\
\hline Casq1 & 10.78 & 0.12 & 0.85 & 0.57 & 0.72 & Muscle & 0.5 & 0.7 \\
\hline Myh4 & 11.96 & 0.13 & 0.45 & 0.31 & 0.43 & Muscle & 0.3 & 0.9 \\
\hline$C \mathrm{~km}$ & 10.78 & 0.14 & 0.44 & 0.46 & 0.76 & Muscle & 0.6 & 0.7 \\
\hline
\end{tabular}

${ }^{a}$ Mean log2 expression in non-induced control mice. Mean fold change in comparison to control: ${ }^{b}$ on day 0 to $3,{ }^{c}$ in week 1 to $2,{ }^{d}$ in week 3 to 4 , ${ }^{\mathrm{e}}$ in the declining disease phase. Fold change of gene expression in arthritic joints from the ${ }^{f}$ TNFa overexpressing model versus control [7], and the ${ }^{9} P G I A$ arthritis model versus control [8], *Differentially expressed epidermal specific genes in arthritic joints from the present study and the TNFa overexpressing model [7]. Ctrl, control; PGIA proteoglycan-induced arthritis; TNFa, tumour necrosis factor alpha.

expression signature was still present (Table S5C and D in Additional file 5).

A comparison of gene expression between week 0 to 2 and week 3 to 4 revealed considerable up-regulation of several epidermal genes (fold changes between 3.8 and 13.9) in the samples collected three to four weeks after onset of arthritis (Table 1).

The expression pattern of 15 differentially expressed genes was verified by qPCR. Of these, 12 genes correlated significantly with the gene expression pattern obtained from the microarray profile, while three genes showed the same expression pattern, but the correlation was not significant. The expression of $B m p 1$ is shown in Figure $3 C$ and D $\left(r^{2}=0.7, p<0.0002\right)$, and the remaining validation data are shown in Figure S6 in Additional file 6 and Figure S7 in Additional file 7 and with the corresponding $\mathrm{r}^{2}$ and $P$-values in Table S8 in Additional file 8.

To identify genes associated with the observed bone pathology, we focused on genes, differentially expressed at the different time-points, which were related to bone and skeleton in the IPA Bio Functions. The genes and associated Bio Functions reflected the bone remodelling process (Table S9 in Additional file 9), and their number and effect size declined over time. The genes and their expression profiles are shown individually in Table S10 in Additional file 10.

\section{Distinctive expression profiles of genes involved in osteoblast and osteoclast functions}

The differentially expressed genes, related to bone, from Table S10 in Additional file 10, were divided into profiles and are shown separately in Table 2 . Profile one encompassed genes with the highest expression on day 0 to 3 with a subsequently declining profile. These were in particular genes encoding proteins involved in OC differentiation and function (Ccl9, Tyrobp, Atp6v0d2, Lif; fold changes between 2.0 and 9.2), in addition to ECM formation and collagen type 1 assembly (Bmp1, Crtap, Tnc, Lox; fold changes between 1.9 and 10.6) [9-14] (Table 2, Figure 4A, and Table S10 in Additional file 10). In profile two, genes with the highest expression in week 1 to 2 , followed by a declining expression pattern, were included. These were in particular genes encoding proteins involved in mineralisation and osteoblast function (Sp7, Spp1, Mgp, Sparc, Enpp1, Bglap1, Ifitm5; fold changes between 1.5 and 4.5) [15-21] (Table 2, Figure 4B and Table S10 in Additional file 10). Integrin-binding sialoprotein (Ibsp; fold change +3.0 ) also belongs to this group [20], but showed the highest expression in week 3 to 4. Moreover, a large group of genes showed a sustained differential expression pattern at day 0 to 3 and week 1 to 2 . These included genes involved in osteoblast functions and ECM formation (Colla1, Col1a2, Ogn, Bgn, Col12a1, Ppib, Lum, Hapln1, Cthrc1, Postn; fold 
Table 2 Groups of genes showing a time-dependent expression pattern

\begin{tabular}{|c|c|c|c|c|c|c|}
\hline Gene symbol & $\mathrm{Ctrl}^{\mathrm{a}}$ & Day 0 to $3^{b}$ & Week 1 to $2^{c}$ & Week 3 to $4^{d}$ & Decline $^{\mathrm{e}}$ & \\
\hline & $\log _{2}$ & \multicolumn{3}{|c|}{ Fold change ( $P$-value) } & & Protein function in relation to bone \\
\hline \multicolumn{7}{|c|}{ Osteoclast function: highest differential expression day 0 to 3} \\
\hline Ccl9 & 6.42 & $2.05(0.01)$ & $1.78(0.01)$ & $1.61(0.10)$ & $1.44(0.10)$ & Stimulates OC motility and polarisation through CCR1. \\
\hline Tyrobp & 10.21 & $4.09(0.03)$ & $3.31(0.02)$ & $2.47(0.06)$ & $1.56(0.33)$ & $\begin{array}{l}\text { Kinase involved in the generation of the actin } \\
\text { cytoskeleton in OC, which is critical for bone resorption. }\end{array}$ \\
\hline Atp6v0d2 & 6.97 & $9.03(0.01)$ & $7.18(0.003)$ & $5.94(0.005)$ & $3.67(0.02)$ & $\begin{array}{l}\text { ATPase proton pump involved in acidification of the } \\
\text { extracellular resorption lacuna created by OC and early } \\
\text { OC differentiation. }\end{array}$ \\
\hline Lif & 5.74 & $2.20(0.01)$ & $1.12(0.22)$ & $0.85(0.39)$ & $0.73(0.10)$ & $\begin{array}{l}\text { Expressed in } O C \text { and modulates the recruitment of } O B \\
\text { to resorption surfaces in a TGF } \beta \text { dependent manner. }\end{array}$ \\
\hline
\end{tabular}

Early osteoblast function: highest differentially expression day 0 to 3

\begin{tabular}{|c|c|c|c|c|c|c|}
\hline Bmp1 & 7.52 & $1.86(0.07)$ & $1.67(0.10)$ & $1.52(0.13)$ & $1.28(0.30)$ & $\begin{array}{l}\text { Metalloproteinase that may play a role on several levels } \\
\text { of bone formation. It processes the c-terminal end of } \\
\text { pro-collagen type I, activates other BMPs and processes } \\
\text { BGN and DMP1. Expressed in patients with arthritis and } \\
\text { acute fractures. }\end{array}$ \\
\hline Crtap & 6.84 & $2.69(0.02)$ & $2.43(0.01)$ & $1.66(0.12)$ & $1.12(0.77)$ & $\begin{array}{l}\text { Scaffolding protein that associates with others to } \\
\text { hydroxylate collagen type I chains. Associated with } \\
\text { osteogenesis imperfecta. }\end{array}$ \\
\hline Tnc & 9.19 & $3.01(0.03)$ & $2.67(0.03)$ & $2.09(0.05)$ & $1.72(0.11)$ & $\begin{array}{l}\text { Pro-inflammatory extracellular matrix protein, expressed } \\
\text { in synovium and blood in RA patients. Involved in } \\
\text { extracellular matrix remodelling, where it is bound by } \\
\text { periostin. }\end{array}$ \\
\hline Lox & 7.13 & $4.51(0.11)$ & $3.52(0.14)$ & $2.49(0.23)$ & $1.57(0.49)$ & $\begin{array}{l}\text { Catalyses cross-linking of collagen type I. Is activated } \\
\text { by BMP1. }\end{array}$ \\
\hline
\end{tabular}

Late osteoblast function: highest differentially expression week 1 to 2 or week 3 to 4

\begin{tabular}{|c|c|c|c|c|c|c|}
\hline$S p 7$ & 6.43 & $1.02(0.90)$ & $1.67(0.04)$ & $1.19(0.25)$ & $1.01(0.95)$ & $\begin{array}{l}\text { Transcription factor with a critical role in osteoblast } \\
\text { differentiation. }\end{array}$ \\
\hline Spp 1 & 8.37 & $2.90(0.05)$ & $4.46(0.00003)$ & $3.49(0.003)$ & $1.98(0.14)$ & $\begin{array}{l}\text { OB marker, expressed in } \mathrm{OB}, \mathrm{OC} \text {, and osteocytes. } \\
\text { Inhibits formation and growth of hydroxyapatite by } \\
\text { binding the crystals. Promotes attachment of OC to } \\
\text { bone under control of Acp5 phosphatase. }\end{array}$ \\
\hline Mgp & 10.45 & $2.61(0.06)$ & $3.33(0.04)$ & $2.45(0.07)$ & $1.65(0.21)$ & Inhibitor of bone mineralisation. \\
\hline Sparc & 11.77 & $2.17(0.04)$ & $2.48(0.03)$ & $2.13(0.04)$ & $1.68(0.07)$ & $\begin{array}{l}\text { The protein binds hydroxyapatite when bound to } \\
\text { collagen type I in vitro. Sparc null mice have normal } \\
\text { collagen content in bone, but reduced bone formation } \\
\text { and numbers of OC and OB. }\end{array}$ \\
\hline Enpp1 & 9.08 & $2.72(0.01)$ & $3.19(0.0003)$ & $2.52(0.01)$ & $1.60(0.15)$ & $\begin{array}{l}\text { Expression is induced in OB by MDK. Essential for } \\
\text { converting extracellular ATP to inorganic } \\
\text { pyrophosphate, thus controlling the levels and } \\
\text { functions in bone mineralization and soft tissue } \\
\text { calcification. Essential for normal bone development. }\end{array}$ \\
\hline Bglap 1 & 9.05 & $0.75(0.62)$ & $2.63(0.0004)$ & $1.82(0.04)$ & $1.37(0.13)$ & $\begin{array}{l}\text { OB marker and serum marker of bone formation. } \\
\text { Expressed in the late mineralisation phase. The exact } \\
\text { role of the protein in bone is, however, debated as } \\
\text { data is controversial. }\end{array}$ \\
\hline Ifitm5 & 6.67 & $1.25(0.11)$ & $1.47(0.03)$ & $1.35(0.05)$ & $1.14(0.27)$ & Expressed in $\mathrm{OB}$ and involved in mineralisation. \\
\hline Ibsp & 10.67 & $2.22(0.02)$ & $2.59(0.01)$ & $2.99(0.01)$ & $2.19(0.02)$ & $\begin{array}{l}\text { Marker of late } \mathrm{OB} \text { differentiation. Expressed in } \mathrm{OB}, \mathrm{OC} \text {, } \\
\text { hypertrophic chondrocytes and osteocytes. Binds to the } \\
\text { AvB3 integrin and hydroxyapatite, probably mediating } \\
\text { cell attachment to matrix. Nucleates hydroxyapatite. }\end{array}$ \\
\hline
\end{tabular}

Sustained high expression week 0 to 2

$\begin{array}{llllll}\text { Col1a2 } & 9.94 & \mathbf{1 . 8 8}(\mathbf{0 . 0 8}) \quad 2.25(\mathbf{0 . 0 5}) \quad 2.03(0.06) & & 1.69(0.10) & \begin{array}{l}\text { This gene encodes the alpha2 chain of collagen type I. } \\ \text { Collagen type I is the most abundant protein in bone } \\ \text { and a marker of OB activity. }\end{array}\end{array}$


Table 2 Groups of genes showing a time-dependent expression pattern (Continued)

\begin{tabular}{|c|c|c|c|c|c|c|}
\hline Col1a1 & 9.84 & $1.80(0.11)$ & $2.25(0.05)$ & $1.92(0.09)$ & $1.69(0.14)$ & $\begin{array}{l}\text { This gene encodes the alpha1 chain of collagen type I. } \\
\text { Collagen type I is the most abundant protein in bone } \\
\text { and a marker of OB activity. }\end{array}$ \\
\hline Ogn & 7.83 & $2.28(0.07)$ & $3.88(0.02)$ & $2.16(0.09)$ & $1.43(0.34)$ & $\begin{array}{l}\text { Proteoglycan belonging to the SLRP family. The protein } \\
\text { is processed by BMP1 and regulates collagen type I } \\
\text { fibrillogenesis. }\end{array}$ \\
\hline Bgn & 10.63 & $2.18(0.04)$ & $2.21(0.03)$ & $1.63(0.09)$ & $1.08(0.72)$ & $\begin{array}{l}\text { Proteoglycan belonging to the SLRP family. KO mice } \\
\text { have reduced collagen synthesis, reduced bone mass } \\
\text { and production of bone precursor cells. The protein is } \\
\text { processed by BMP1. }\end{array}$ \\
\hline Col12a1 & 8.24 & $4.59(0.04)$ & $4.81(0.04)$ & $2.98(0.08)$ & $1.75(0.25)$ & $\begin{array}{l}\text { Expressed by OB in areas of bone formation. COL12A1 } \\
\mathrm{KO} \text { mice have skeletal abnormalities with less } \\
\text { mechanical strength and reduced matrix deposition. }\end{array}$ \\
\hline Ppib & 7.45 & $2.17(0.04)$ & $2.27(0.07)$ & $1.49(0.14)$ & $1.16(0.64)$ & $\begin{array}{l}\text { Associates with other proteins to hydroxylate collagen } \\
\text { type I chains. Associated with osteogenesis imperfecta. }\end{array}$ \\
\hline Lum & 10.18 & $3.37(0.04)$ & $3.97(0.03)$ & $2.78(0.05)$ & $1.69(0.18)$ & $\begin{array}{l}\text { Proteoglycan belonging to the SLRP family (same as } \\
\text { BGN). }\end{array}$ \\
\hline Hapln1 & 6.72 & $1.69(0.15)$ & $3.10(0.01)$ & $2.88(0.005)$ & $2.08(0.01)$ & $\begin{array}{l}\text { Involved in cartilage biosynthesis by linking aggrecans } \\
\text { and hyalyron acid. Polymorphism in this gene is } \\
\text { associated with osteophyte formation in osteoarthritis } \\
\text { and it is located in a susceptibility locus of AS. }\end{array}$ \\
\hline Postn & 8.52 & $10.33(0.07)$ & $9.76(0.07)$ & $4.97(0.12)$ & $2.53(0.29)$ & $\begin{array}{l}\text { Promotes cell survival of preosteoblasts and OB. } \\
\text { Increases activation of pro-lysyl oxidase, which } \\
\text { cross-links collagen type I. }\end{array}$ \\
\hline Cthrc1 & 8.46 & $4.78(0.06)$ & $6.79(0.05)$ & $3.50(0.10)$ & $1.65(0.43)$ & $\begin{array}{l}\text { Molecule that stimulates bone formation, secreted } \\
\text { by OC. }\end{array}$ \\
\hline \multicolumn{7}{|l|}{ Others } \\
\hline Igf1 & 9.68 & $1.94(0.04)$ & $2.61(0.03)$ & $1.82(0.05)$ & $1.18(0.59)$ & $\begin{array}{l}\text { Growth factor positively regulating bone formation. } \\
\text { Regulates bone mineral density. }\end{array}$ \\
\hline Pappa & 5.99 & $2.24(0.0002)$ & $1.20(0.06)$ & $1.08(0.11)$ & $0.96(0.68)$ & $\begin{array}{l}\text { IGF-dependent proteinase that regulates the } \\
\text { bioavailability of IGF. Expressed in fibroblasts, } \\
\text { chondrocytes and OB. Pappa KO mice have reduced } \\
\text { bone formation and delayed fracture-healing. }\end{array}$ \\
\hline Dmp1 & 8.30 & $0.74(0.42)$ & $1.2(0.59)$ & $1.81(0.17)$ & $1.47(0.30)$ & $\begin{array}{l}\text { Extracellular matrix protein that is processed by BMP1 } \\
\text { and involved in mineralisation of extracellular matrix. } \\
\text { Expressed by hypertrophic chondrocytes, osteocytes, } \\
\text { and OB. }\end{array}$ \\
\hline \multicolumn{7}{|c|}{ Tissue degradation } \\
\hline Mmp13 & 7.57 & $13.15(0.02)$ & $17.33(0.02)$ & $8.93(0.02)$ & $4.53(0.05)$ & $\begin{array}{l}\text { Bone resorption, OC- and osteoprogenitor } \\
\text { differentiation. }\end{array}$ \\
\hline Ctsk & 7.82 & $11.02(0.04)$ & $11.75(0.04)$ & $7.58(0.04)$ & $4.80(0.08)$ & Bone resorption. Principle enzyme degrading osteoid. \\
\hline Mmp3 & 7.24 & $23.11(0.02)$ & $11.87(0.01)$ & $5.24(0.04)$ & $2.94(0.11)$ & Metalloproteinase associated with arthritis. \\
\hline Timp1 & 7.53 & $19.45(0.002)$ & $9.33(0.001)$ & $5.30(0.03)$ & $3.44(0.02)$ & Inhibitor of metalloproteinases. \\
\hline Mmp9 & 7.15 & $4.24(0.02)$ & $3.79(0.02)$ & $2.95(0.04)$ & $2.20(0.08)$ & Resorption, OC- and osteoprogenitor differentiation. \\
\hline Ctss & 8.32 & $3.62(0.04)$ & $2.99(0.05)$ & $2.29(0.08)$ & $1.68(0.20)$ & Expressed in hypertrophic chondrocytes and OC. \\
\hline Mmp19 & 5.99 & $2.18(0.02)$ & $2.05(0.01)$ & $1.45(0.16)$ & $1.26(0.09)$ & Degradation of extracellular tissue. \\
\hline Mmp14 & 7.92 & $2.63(0.02)$ & $2.82(0.02)$ & $2.11(0.02)$ & $1.77(0.05)$ & Involved in tissue destruction in RA. \\
\hline Acp5 & 7.30 & $3.68(0.02)$ & $3.46(0.03)$ & $3.59(0.03)$ & $2.50(0.03)$ & $\begin{array}{l}\text { The encoded protein is a phosphatase, also called Trap. } \\
\text { It is a marker of OC function and is extensively } \\
\text { expressed in OC. It is activated by Cathepsin K and } \\
\text { dephosphorylates SPP1 and IBSP. Plays an inhibitory } \\
\text { role in collagen type I synthesis, degradation, and } \\
\text { mineralisation. }\end{array}$ \\
\hline \multicolumn{7}{|c|}{ Genes of the BMP pathway } \\
\hline Bmp2 & 7.16 & $1.67(0.30)$ & $1.68(0.29)$ & $1.24(0.63)$ & $1.26(0.59)$ & Ligand of the BMP pathway. \\
\hline Bmpr1a & 6.88 & $1.84(0.13)$ & $2.01(0.10)$ & $1.91(0.11)$ & $1.15(0.72)$ & Type I receptor of the BMP pathway. \\
\hline
\end{tabular}


Table 2 Groups of genes showing a time-dependent expression pattern (Continued)

\begin{tabular}{|c|c|c|c|c|c|c|}
\hline Bmpr2 & 8.36 & $2.05(0.04)$ & $1.65(0.08)$ & $1.40(0.15)$ & $1.30(0.28)$ & Receptor type II in the BMP pathway. \\
\hline Smad2 & 7.23 & $2.05(0.14)$ & $2.14(0.12)$ & $1.70(0.22)$ & $1.44(0.37)$ & Regulatory Smad involved in BMP signalling. \\
\hline Smad6 & 7.27 & $0.55(0.08)$ & $0.58(0.0045)$ & $0.72(0.04)$ & $0.76(0.12)$ & Inhibitory Smad antagonising BMP signalling. \\
\hline Smad4 & 8.16 & $1.28(0.18)$ & $1.27(0.19)$ & $1.18(0.32)$ & $1.04(0.84)$ & Co-Smad associating with regulatory Smads. \\
\hline Smad5 & 7.07 & $1.40(0.04)$ & $1.28(0.06)$ & $1.20(0.17)$ & $0.99(0.92)$ & Regulatory Smad involved in BMP signalling. \\
\hline Bmp4 & 7.68 & $0.59(0.04)$ & $0.68(0.04)$ & $0.99(0.95)$ & $0.95(0.61)$ & Ligand of the BMP pathway. \\
\hline Bmp6 & 8.44 & $0.62(0.07)$ & $0.75(0.15)$ & $0.88(0.67)$ & $0.93(0.63)$ & Ligand of the BMP pathway. \\
\hline Bmp7 & 5.82 & $0.78(0.19)$ & $0.86(0.31)$ & $0.94(0.67)$ & $1.26(0.17)$ & Ligand of the BMP pathway. \\
\hline Inhba & 7.20 & $5.65(0.01)$ & $3.94(0.01)$ & $2.09(0.07)$ & $1.17(0.77)$ & $\begin{array}{l}\text { Non-steroidal hormone reported to increase bone } \\
\text { formation in transgenic mice overexpressing human } \\
\text { inhibin A. Associated with human arthritis. }\end{array}$ \\
\hline Acvr2a & 7.23 & $1.27(0.33)$ & $1.29(0.03)$ & $1.18(0.04)$ & $0.91(0.34)$ & Type II receptor of the TGF $\beta$ pathway. \\
\hline Acvr2b & 6.21 & $0.80(0.01)$ & $0.73(0.0034)$ & $0.76(0.03)$ & $0.85(0.29)$ & Type II receptor of the TGF $\beta$ pathway. \\
\hline \multicolumn{7}{|c|}{ Genes of the WNT pathway } \\
\hline Fzd1 & 6.91 & $1.70(0.05)$ & $1.57(0.05)$ & $1.39(0.08)$ & $1.18(0.37)$ & Receptor of the WNT pathway. \\
\hline Hif1a & 8.35 & $4.23(0.02)$ & $3.56(0.02)$ & $2.49(0.03)$ & $1.43(0.34)$ & $\begin{array}{l}\text { Regulates the cellular response to hypoxia during } \\
\text { endochondral bone formation and inhibits WNT } \\
\text { signalling in OB in cooperation with Sp7. }\end{array}$ \\
\hline Sost & 7.28 & $0.48(0.03)$ & $0.61(0.02)$ & $0.62(0.03)$ & $0.73(0.15)$ & WNT antagonist and marker of mature osteocytes. \\
\hline Ndrg2 & 10.56 & $0.18(0.01)$ & $0.31(0.0014)$ & $0.37(0.01)$ & $0.52(0.01)$ & $\begin{array}{l}\text { Down-regulates WNT-signalling mediated TCF- } \\
\text { promotor activity and GSK3 } \beta \text { phosphorylation } \\
\text { synergistically with PRA1. }\end{array}$ \\
\hline Dkk1 & 7.19 & $0.67(0.18)$ & $0.85(0.25)$ & $1.15(0.32)$ & $1.09(0.43)$ & Antagonist of the WNT pathway. \\
\hline$T c f 4$ & 7.96 & $1.46(0.09)$ & $1.73(0.03)$ & $1.30(0.28)$ & $0.99(0.94)$ & Transcription factor of the WNT pathway. \\
\hline
\end{tabular}

${ }^{a}$ Mean log2 expression in non-induced control mice. Mean fold change and p-value in comparison to control: ${ }^{b}$ on day 0 to $3,{ }^{c}$ in week 1 to $2,{ }^{d}$ in week 3 to $4,{ }^{e}$ in the declining disease phase. The highest differential expression value and corresponding p-value of each gene are shown in bold italics. AS, ankylosing spondylitis; BMP, bone morphogenetic protein; BGN, biglycan; CCR1, C-C chemokine receptor type 1; Ctrl, control; DMP1, dentin matrix acidic phosphoprotein1; IGF, insulin-like growth factor; KO, knockout; MDK, midkine; OB, osteoblast; OC, osteoclast; RA, rheumatoid arthritis; SLRP, leucine rich repeat containing 6; TCF, T-cell-specific transcription factor; TGF $\beta$, transforming growth factor beta.

changes between 2.2 and 10.3) [13,14,22-27] (Table 2). Finally, tissue destruction was reflected by up-regulation of the genes for four metalloproteinases (MMPs): the MMP inhibitor Timp1; acid phosphatase 5 (Acp5); cathepsin K [28]; cathepsin S [29], and additional cathepsins. These genes were among the most highly expressed, throughout disease development (Table 1, Table 2 and Table S10 in Additional file 10).

\section{Differential expression of genes belonging to the BMP pathway}

Differentially expressed genes related to the BMP pathway included the genes encoding the BMP type I and type II receptors (Bmprla and Bmpr2, fold change +2 at week 1 to 2 and day 0 to 3 , respectively), and proteins downstream of the BMP signalling pathway (Smad2 and Smad6, fold change +2.1 at week 1 to 2 and -1.8 at day 0 to 3 , respectively) (Table 2, Figure 5 and Table S10 in Additional file 10). The BMP ligand $B m p 2$ (fold change +1.7 at day 0 to 3) together with $\operatorname{Smad4}$ (fold change +1.3 at day 0 to 3 ) and Smad5 (fold change +1.4 at day 0 to 3 ) showed the same marginal change in expression pattern. The BMP ligands Bmp4, Bmp6, and Bmp7 were slightly downregulated (fold change between -1.7 to -1.3 at day 0 to 3 ).

High upregulation of the gene for Inhibin beta A (Inhba; fold change +5.6 at day 0 to 3 ) was found, in addition to minor expression changes in the genes of some of the transforming growth factor beta (TGF $\beta$ ) receptors $($ Acvr $2 a$ and Acvr2b) bound by this protein (Table 2 and Figure 5A).

\section{Differential expression of genes belonging to the WNT pathway}

Within the group of genes related to the WNT pathway, the genes for the receptor FZD1 (fold change +1.7 at day 0 to 3 ) and transcription factor TCF4 (fold change +1.7 at week 1 to 2 ) were differentially expressed, in addition to a number of WNT inhibitors. These included the hypoxia-induced Hifla, which showed more than 4-fold up-regulation and Sost and Ndrg2, which were between 2 and 5.6-fold downregulated. The well-described WNT inhibitor $D k k 1$ was slightly downregulated (Table 2 and Table S10 in Additional file 10). 

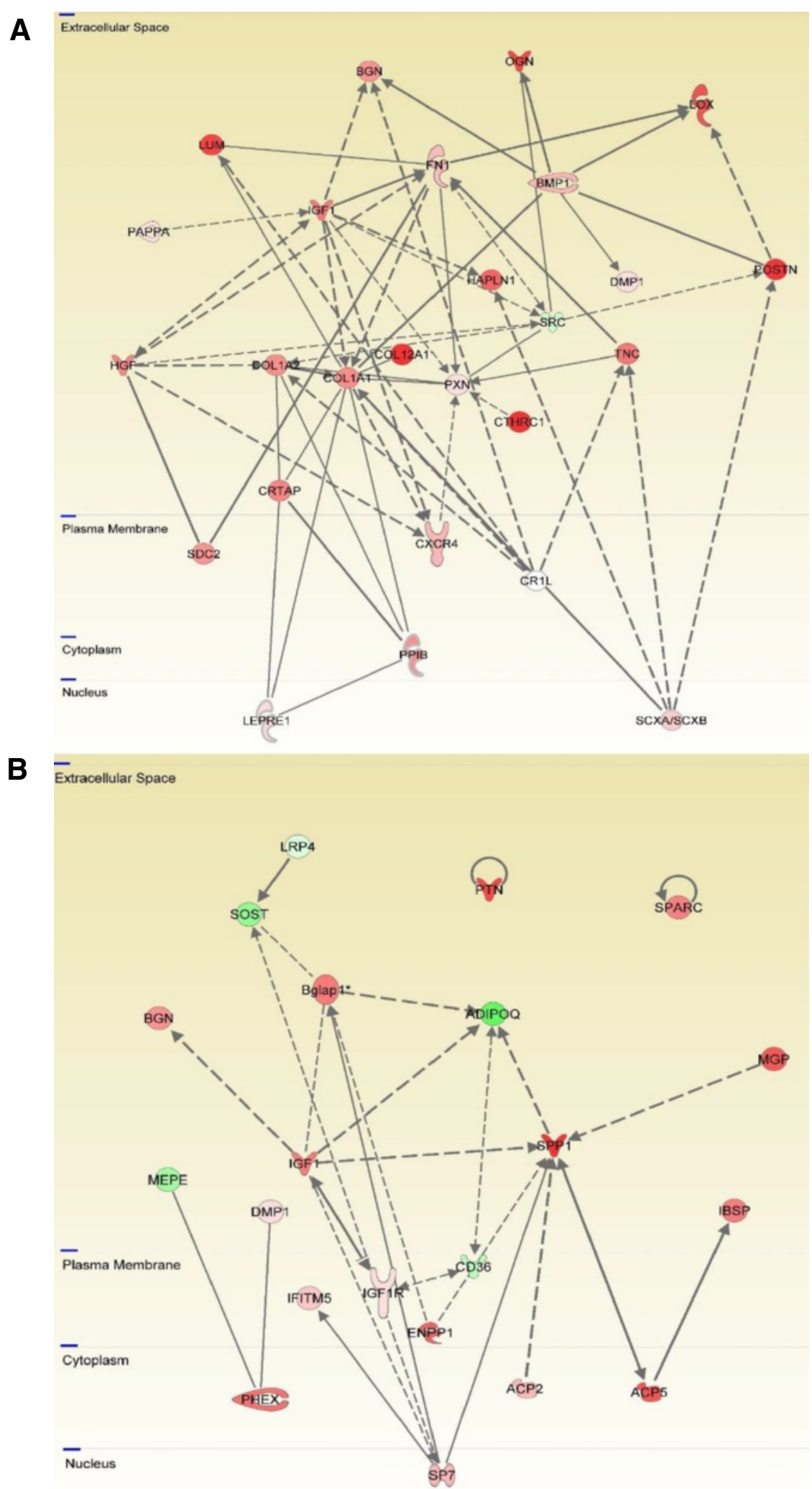

Figure 4 (See legend on next page.) 
(See figure on previous page.)

Figure 4 Gene expression networks during osteoblast activity in early and late phases of joint inflammation. A) A network of genes related to osteoblast activity, in particular collagen type I assembly and cross-linking, during the early phase of clinical disease. Colours and colour intensity indicate upregulation (red) or downregulation (green) regulation of genes at day 0 to 3 , where most of the genes showed the greatest fold change in comparison to non-induced controls. One exception is Dmp1, which became upregulated at week 3 to 4 . B) A network of genes related to osteoblast activity, in particular mineralisation, during the late phase of clinical disease. Colours and colour intensity indicate upregulation (red) or downregulation (green) regulation of genes at week 1 to 2, where most of the genes showed the greatest fold change in comparison to non-induced controls. One exception is Ibsp, which was most highly upregulated in week 3 to 4.

\section{Comparison to genome-wide association studies in human arthritis}

Some of the genes differentially expressed in the herein presented study have been linked to human arthritis in genome-wide association studies (GWAS) (Table 2). Of those genes, several are involved in cartilage- and bone remodelling (underlined in Table 3).

\section{Discussion}

In this study, we have shown that in CIA, major histopathological changes, comprising inflammation as well as bone formation and ankylosis, occur within the first two weeks after the inflammatory symptoms become clinically apparent in a joint. Moreover, we have shown that the histopathology is reflected at the gene expression level, where a number of genes, coding for proteins important in inflammation and bone remodelling, are differentially expressed within the same time period after disease onset. This suggests that the CIA model is relevant for the osteoproliferative inflammatory arthritis in PsA and AS.

Bone formation in the murine CIA model has been described as starting in the subacute inflammatory disease phase, two to four weeks after onset of arthritis, but mainly playing a role in the healing state two to three months after onset [2]. However, no studies disclose any molecular details regarding bone formation throughout the arthritis disease course. Recently, Schett et al. [3] performed a histological study of new bone formation in the rat CIA and AIA models. In their study, periosteal proliferation was noted on day 3 (CIA) and day 5 (AIA) after onset of arthritis and new bone formation peaked at day 27 after onset of arthritis in both models.

The link between joint inflammation and bone remodelling is not clear. In human arthritis, areas with inflammation were shown to be predictive of bone formation [42], but bone formation does not seem to be blocked by anti-tumor necrosis factor alpha (TNF $\alpha$ ) treatment [43]. In the present study, we have shown that in the murine CIA model, bone formation is (1) initiated during active inflammation, (2) develops in parallel with the inflammation, and (3) that the bone mineralises and remodels when clinical inflammatory signs are declining.

The molecular events underlying inflammation and bone remodelling were investigated using gene expression profiling. The results are based on a first kinetic mapping of global gene expression in the joint during clinical onset and development of arthritis. Expression of specific genes might differ depending on the microanatomical site within the joint and future studies of proteins important in the interplay between inflammation and bone formation should address this. We found that the bone pathology observed histologically was reflected in the Bio Functions, significantly associated with differentially expressed genes, from onset to decline of clinical arthritis in the joint. Moreover, genes involved in inflammation and bone remodelling were co-expressed during the first two weeks after onset of clinical arthritis and, hereafter, the gene expression gradually normalized to control levels, while the clinical inflammation was declining. A muscle-specific signature was observed among the most downregulated genes during the first two weeks after onset of arthritis. This may reflect muscle inactivity and atrophy observed in the model [44] and may translate to the impaired muscle function observed in arthritis patients. However, since animals in the acute disease phase also lose weight, this may partly explain some of the gene expression changes observed in muscle-specific genes.

Several metalloproteinases and cathepsins associated with human arthritis showed sustained, high expression during the entire disease course (Table 1, and Table S10 in Additional file 10). These reflect tissue destruction, in addition to being a link between bone erosion and bone formation. MMP9 and MMP13 have been shown to play a crucial role in endochondral bone formation, as well as in matrix degradation and in $\mathrm{OC}$ and osteoprogenitor differentiation $[45,46]$.

Genes with the highest fold change at day 0 to 3 after onset of clinical arthritis reflected osteoclast function and differentiation, in addition to ECM formation and collagen type 1 assembly, while genes showing the highest fold change at week 1 to 2 or week 3 to 4 encompassed a well-known group of $\mathrm{OB}$ markers and genes involved in mineralisation (Table 2, Figure 4A and B). These variations in gene expression pattern mirror the development in $\mathrm{OB}$ differentiation and function, as gene expression is specific for the differential stages of the OB [47]. The gene expression profiles followed the histological observations: bone erosion, periosteal proliferation and osteoid secretion, was observed in the initial phase followed by onset of 
A

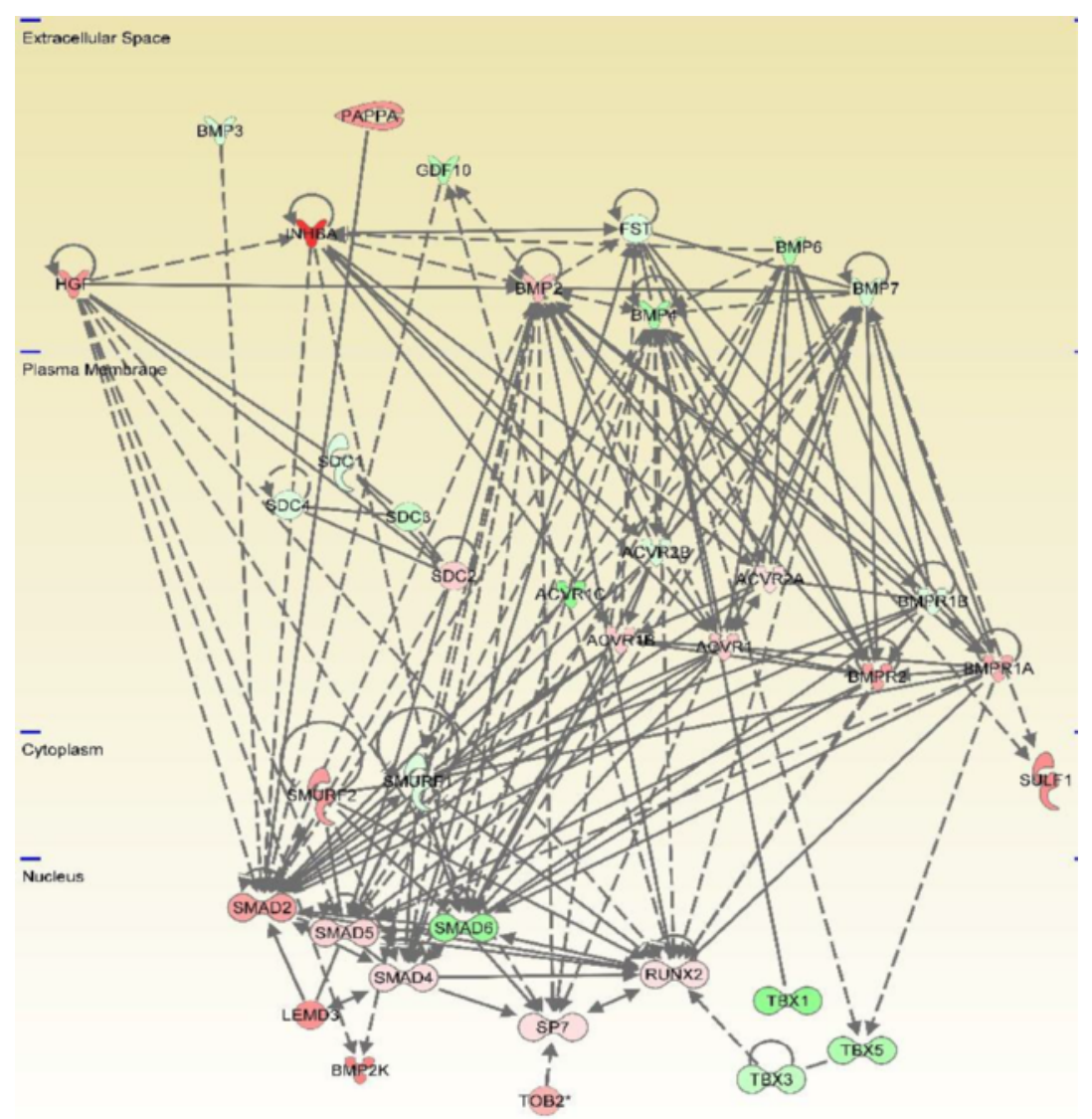

B

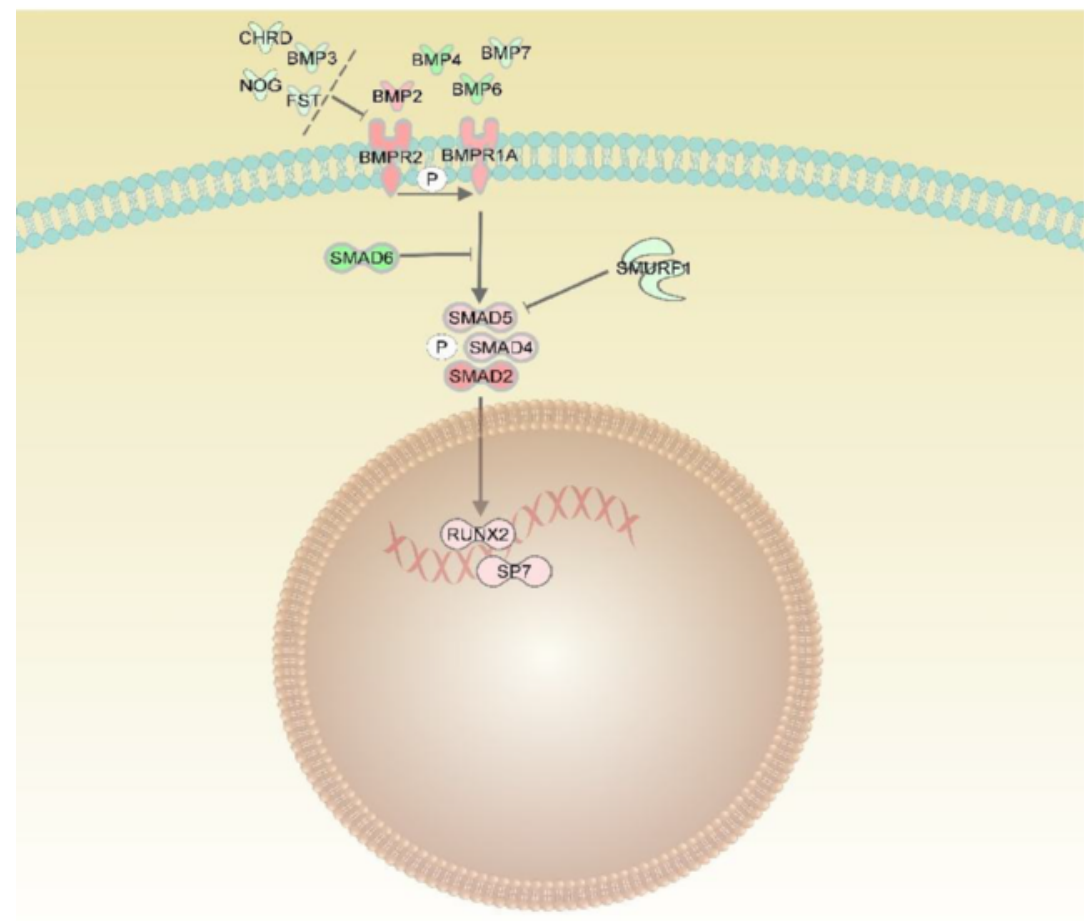

Figure 5 Differentially expressed genes related to BMP signalling at day 0 to 3 of arthritis in comparison to non-induced controls.

Regulation of genes is indicated by colour and colour intensity (red = upregulated, green= downregulated). (A) Network of BMP related genes in general. (B) Functional pathway of BMP signalling. BMP, bone morphogenetic protein. 
Table 3 Differential expression of genes associated with human arthritis in GWAS studies

\begin{tabular}{|c|c|c|c|c|c|c|}
\hline Gene symbol & $\mathrm{Ctrl}^{\mathrm{a}}$ & $\begin{array}{l}0 \text { to } 3 \mathrm{~d} \\
\text { vs. } \mathrm{Ctrr}^{\mathrm{b}}\end{array}$ & $\begin{array}{l}1 \text { to } 2 \mathrm{w} \\
\text { vs. } \mathrm{Ctrl}^{\mathrm{c}}\end{array}$ & $\begin{array}{l}3 \text { to } 4 w \\
\text { vs. } \mathrm{Ctrr}^{\mathrm{d}}\end{array}$ & $\begin{array}{l}\text { Decline } \\
\text { vs. Ctrl }\end{array}$ & Protein function \\
\hline & $\log 2$ & \multicolumn{4}{|c|}{ Fold change ( $P$-value) } & \\
\hline \multicolumn{7}{|c|}{ Ankylosing spondylitis } \\
\hline Hapln1 & 6.72 & $1.69(0.15)$ & $3.10(0.01)$ & $2.89(0.005)$ & $2.08(0.01)$ & $\begin{array}{l}\text { Involved in cartilage development and bone formation. } \\
\text { Associated with osteophyte formation in OA [30]. }\end{array}$ \\
\hline Edil3 & 5.58 & $1.53(0.14)$ & $2.95(0.003)$ & $3.07(0.005)$ & $2.33(0.11)$ & $\begin{array}{l}\text { Integrin ligand with a proposed role in cartilage } \\
\text { development and angiogenesis. Inhibitor of the WNT } \\
\text { pathway [30]. }\end{array}$ \\
\hline Ano6 & 7.22 & $2.25(0.05)$ & $1.88(0.04)$ & $1.61(0.14)$ & $1.19(0.60)$ & $\begin{array}{l}\text { Regulates phosphatidylserine exposure on the cell } \\
\text { surface, which is essential for mineralisation of bone } \\
\text { and involved in osteoclast formation }[30,31] \text {. }\end{array}$ \\
\hline Psmgl & 6.95 & $2.04(0.002)$ & $1.91(0.002)$ & $1.37(0.03)$ & $1.03(0.78)$ & $\begin{array}{l}\text { Proteasome Assembly Chaperone 1. The gene is, in addition, } \\
\text { associated with inflammatory bowel disease [32]. }\end{array}$ \\
\hline \multicolumn{7}{|c|}{ Rheumatoid arthritis } \\
\hline Anapc4 & 6.85 & $1.77(0.0008)$ & $1.91(0.0003)$ & $1.45(0.02)$ & $1.18(0.45)$ & $\begin{array}{l}\text { An SNP close to this gene was associated with RA } \\
\text { susceptibility [33]. The encoded protein is an E3 ubiquitin } \\
\text { ligase involved in control of the cell cycle, muscle cell } \\
\text { function, and function of neurons [34]. }\end{array}$ \\
\hline $\mathrm{Cd} 84$ & 5.61 & $3.07(0.01)$ & $3.01(0.004)$ & $2.17(0.02)$ & $1.51(0.12)$ & $\begin{array}{l}\text { Membrane protein involved in immune function. High } \\
\text { expression of the gene was associated with a positive } \\
\text { response to Etanercept treatment [35]. }\end{array}$ \\
\hline II6st & 9.44 & $2.41(0.03)$ & $1.79(0.06)$ & $1.52(0.10)$ & $1.09(0.76)$ & $\begin{array}{l}\text { Signal transducing subunit for cytokines belonging to } \\
\text { the IL-6 family. Activates Stat-3, which plays a role in OC } \\
\text { and OB differentiation and their interaction [36]. }\end{array}$ \\
\hline Ptpn2 & 6.68 & $1.74(0.06)$ & $1.78(0.02)$ & $1.32(0.30)$ & $1.46(0.16)$ & $\begin{array}{l}\text { Protein phosphatase involved in T-cell activation by } \\
\text { regulation of the JAK/STAT signalling pathway }[33,37,38] \text {. }\end{array}$ \\
\hline$C d k 6$ & 5.88 & $2.51(0.10)$ & $2.35(0.08)$ & $2.11(0.08)$ & $1.64(0.21)$ & $\begin{array}{l}\text { Cyclin-dependent kinase involved in proliferation of } \\
\text { lymphocytes [39]. }\end{array}$ \\
\hline Prkca & 7.42 & $0.48(0.17)$ & $0.65(0.26)$ & $0.55(0.16)$ & $0.61(0.32)$ & $\begin{array}{l}\text { Kinase involved in activation of NFKB and AP-1 transcription } \\
\text { factors [39]. }\end{array}$ \\
\hline Prkch & 7.20 & $1.36(0.04)$ & $1.43(0.07)$ & $1.58(0.06)$ & $0.99(0.95)$ & $\begin{array}{l}\text { Serine/threonine kinase. The association with RA is } \\
\text { suggestive [38]. }\end{array}$ \\
\hline \multicolumn{7}{|l|}{ Osteoarthritis } \\
\hline Gn/3 & 7.81 & $2.41(0.11)$ & $2.10(0.08)$ & $2.17(0.07)$ & $1.47(0.34)$ & $\begin{array}{l}\text { Nucleostemin. Increased in in vitro cultures of chondrocytes } \\
\text { from patients with OA [40]. }\end{array}$ \\
\hline Glt8d & 7.18 & $1.97(0.03)$ & $1.99(0.02)$ & $1.43(0.05)$ & $1.13(0.71)$ & Involved in glycosylation of cartilage proteins [40]. \\
\hline Pla2g & 5.96 & $1.47(0.16)$ & $1.67(0.04)$ & $2.06(0.03)$ & $1.71(0.04)$ & $\begin{array}{l}\text { Cytosolic phospholipase A2 enzyme. mRNA transcript was } \\
\text { abundantly expressed in chondrocytes from OA patients [41]. }\end{array}$ \\
\hline Ptgs2 & 6.91 & $2.66(0.01)$ & $1.72(0.07)$ & $1.15(0.41)$ & $1.56(0.03)$ & $\begin{array}{l}\text { Cyclooxygenase } 2 \text { (COX-2). mRNA transcript was abundantly } \\
\text { expressed in chondrocytes from OA patients [41]. }\end{array}$ \\
\hline Col12a1 & 8.24 & $4.56(0.04)$ & $4.82(0.01)$ & $2.97(0.04)$ & $1.74(0.22)$ & $\begin{array}{l}\text { A SNP close to this gene has been associated with OA } \\
\text { susceptibility [40]. The encoded protein is expressed by } \\
\text { OB in areas of bone formation. KO mice have skeletal } \\
\text { abnormalities with less mechanical strength and } \\
\text { reduced matrix deposition [24]. }\end{array}$ \\
\hline
\end{tabular}

${ }^{a}$ Mean log2 expression in non-induced control mice. Mean fold change and $P$-value in comparison to control: ${ }^{b}$ on day 0 to 3 , ${ }^{c}$ in week 1 to $2,{ }^{d}$ in week 3 to 4 , ${ }^{e}$ in the declining disease phase. Genes shown in bold are encoding proteins with a known function in cartilage- or bone remodelling. Ctrl, control; GWAS, genome-wide association studies; IL-6, interleukin 6; KO, knockout; NFKB, nuclear factor kappa B; OA, osteoarthritis; OB, osteoblast; OC, osteoclast; RA, rheumatoid arthritis; WNT, wingless-type.

endochondral bone formation and mineralisation in weeks 1 to 2 . The data support a model for bone remodelling during arthritis, where bone erosion is mainly taking place during the very early phase of clinical arthritis, with the onset of tissue remodelling and bone formation following shortly after, developing in parallel with the inflammation.
When the inflammatory response ceases, the addition of new bone decreases, and the hitherto created bone is remodelled and mineralised. As suggested by the histological results, the newly formed bone may be created in different processes depending on the microanatomical site. Thus, addition of bone in the periosteum takes place 
first, without preceding cartilage formation, while osteophytes at the joint margin are created in a process resembling endochondral ossification (Figure 6). A comparison of the present data to the proteoglycan-induced arthritis (PGIA) model reveals a high degree of similarity concerning the mixed anabolic and catabolic bone remodelling profile [8]. In contrast, the TNF $\alpha$-transgenic arthritis mouse model showed a primarily catabolic bone remodelling profile, while genes representing the osteoproliferative response showed no or marginally differential expression [7]. This is in line with a general comprehension of the TNF $\alpha$-transgenic mouse as a mainly erosive model, while the PGIA and CIA models demonstrate osteoproliferative arthritis. All three models showed a strong up-regulation of Mmps and Timp1. Data are compared in Table S10 Additional file 10.

Highly differentially expressed genes encoding proteins involved in bone formation between day 0 to 3 of clinical arthritis are potential links between inflammation and bone formation. Two of these genes are the insulin-like growth factor (IGF)-dependent proteinase pregnancy-associated plasma protein A gene (Pappa) and periostin (Postn). In addition, genes particularly involved in early ECM formation, preceding bone formation, are potential candidates. The PAPP-A protein is an anabolic growth factor in bone in vivo and in vitro $[48,49]$ and regulates bioavailability of Insulin-like growth factor (IGF) involved in bone formation [50], and also differentially expressed. Expression of Pappa is stimulated by inflammatory cytokines in several cell types, including OBs, and macrophages isolated from artherosclerotic lesions $[51,52]$. It has recently been identified as a marker of inflammation in acute coronary syndrome [53]. Furthermore, Pappa knockout mice display disturbed bone formation $[54,55]$, while mice overexpressing Pappa have increased bone formation $[48,49]$. Thus, Pappa expression might be induced in the early inflammatory environment and the protein could be involved in initiating bone formation in the CIA model.

The Postn gene is one of the highly differentially expressed genes with a proposed role in bone remodelling.

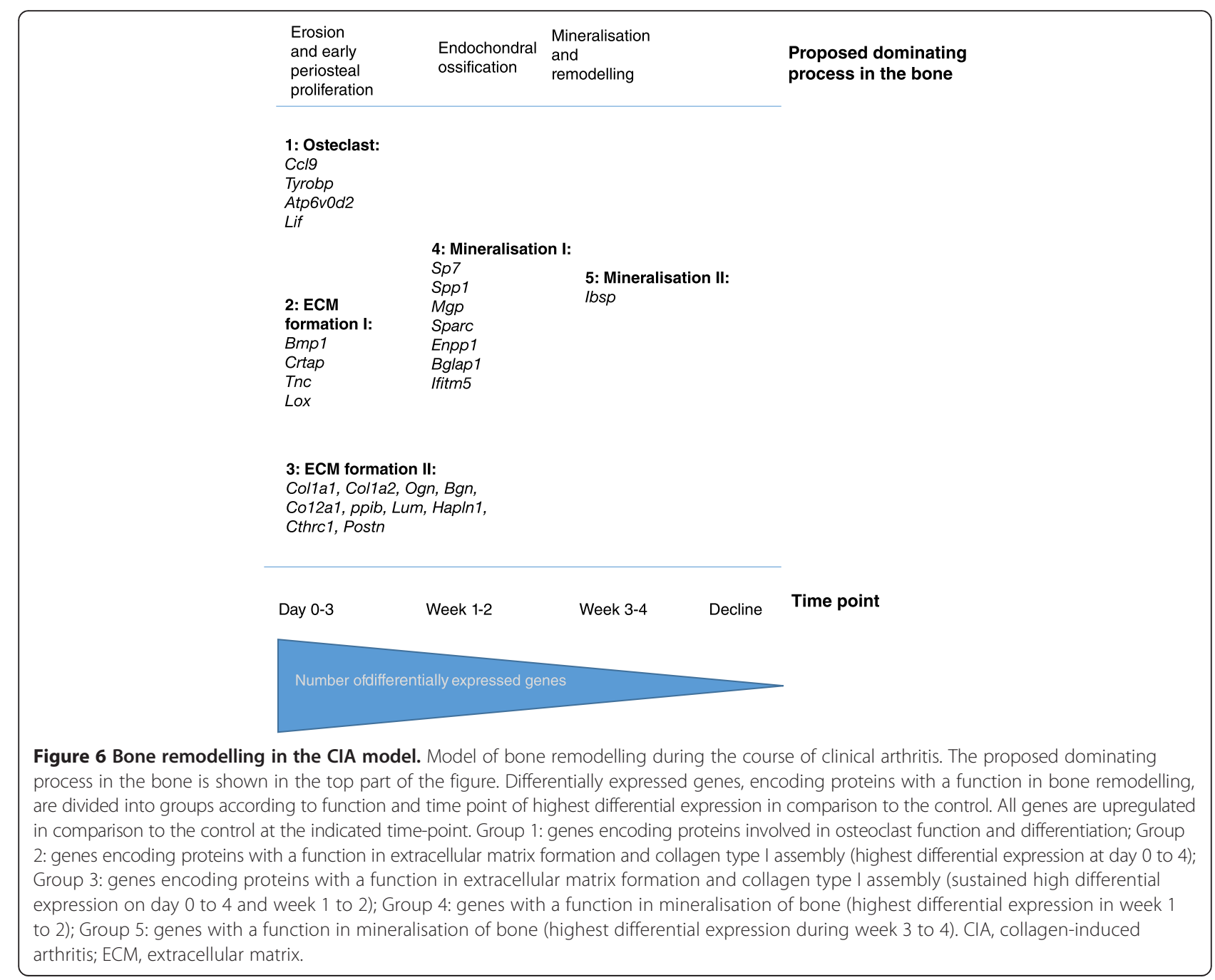


It is preferentially located in the periostium and is reexpressed during fracture repair, mechanical stress, and in RA [14]. The expression is regulated by BMP2 and TGF $\beta$. Overexpression of periostin increases bone formation possibly by promoting cell survival of preosteoblasts and OBs [56]. By binding fibronectin, tenascin and BMP1, it increases the activation of pro-lysyl oxidase, which in turn cross-links collagen [14]. Moreover, BMP1 has been linked to arthritis and bone formation $[57,58]$ and may increase bone formation in several ways.

In weeks 1 to 2 after clinical onset, many genes reflecting the mineralisation of osteoid showed the highest differential expression over time in comparison to control (Table 2 and Figure 4B). Integrin-binding sialoprotein $(I b s p)$ is involved in the formation of crystals, as well as cell attachment to hydroxyapatite [20]. Osteonectin (Sparc) binds and connects hydroxyapatite to collagen type I [21], while osteonectin (Spp1) binds hydroxyapatite crystals, inhibiting their formation [21]. Moreover, these genes also reflect the complexity of interactions between ECM, OCs and OBs, as many of them have dual functions in bone remodelling.

In summary, the network of regulated genes involved in collagen type I assembly represented in Figure 4A, might play an important role in arthritis-associated ECM formation, leading to fibrosis and osteophyte formation.

Of particular interest in arthritis-associated bone remodelling are molecules belonging to the BMP and WNT signalling pathways. In human arthritis, the BMP ligands 2 and 6 [59] and their receptors BMPR1a and BMPR2 [60] were upregulated, while BMP ligands 4 and 5 were downregulated in RA and osteoarthritis (OA) synovium in comparison to normal control samples. Our results showed a similar up-regulation of the genes for the receptors BMPR1a and BMPR2, but down-regulation of Bmp4, Bmp6 and Bmp7 (Figure 5).

One of the strongly upregulated genes in this study is Inhba (Inhibin beta A), which may stimulate the TGF $\beta$ signalling pathway through binding to receptors Acv1b, Avr2a and Avr2b. This non-steroidal hormone regulating follicle-stimulating hormone (FSH) secretion is reported to increase bone formation in a knock-in transgenic mouse [61], and has been associated with human arthritis [62].

A profile of WNT signalling is not distinct in our gene expression data, since most of the genes belonging to this pathway were marginally differentially expressed compared to the control samples. However, a number of WNT inhibitors were differentially expressed. These included the upregulated Hifla. The encoded protein is a hypoxia inducible factor that plays a role in angiogenesis during endochondral bone formation. Together with $\mathrm{Sp} 7$, it inhibits the WNT signalling pathway [63]. Moreover, WNT inhibitors Sost and Ndgr2 were both downregulated and Dkk1, the master regulator of WNT signalling, was slightly downregulated. This could be expected during anabolic bone conditions. Sost and Dkk1 downregulation has been associated with proteoglycan-induced arthritis in mice, and DKK1 with human AS [8].

In Table 3, several genes identified in GWAS of human arthritis are listed together with the expression data from the CIA model found in the present study. The five underlined genes encode proteins with a function in cartilage or bone remodelling, and are potential therapeutic candidate genes. The expression of those genes highlights the importance of the CIA model for studies of osteoproliferative inflammatory arthritic diseases.

\section{Conclusions}

Bone remodelling in the CIA model results in ankylosis within one to two weeks after clinical disease onset and occurs simultaneously with the local inflammatory process in the joint. Furthermore, in this study, we have identified networks of genes involved in early and late bone formation, as well as genes associated with human arthritis, which may provide potential targets for modulating bone formation in arthritis.

Taken together, this suggests that the CIA model is an important tool in investigations of the relationship between inflammation and bone formation in the search for therapeutic targets to prevent ankylosis in inflammatory arthritis.

\section{Additional files}

Additional file 1: Table S2. A and B: Overview of samples used for histology and global gene expression study.

Additional file 2: Figure S1. Illustration of histological bone scores. (A) Bone erosion and formation score 0: no pathological changes. (B) Bone erosion score 2. (C) Bone formation score 2. (D) Bone erosion score 4. (E) Bone formation score 4.

Additional file 3: RMA gene default summary of array data for review.

Additional file 4: Table S4. Table of assay IDs for specific primer/probe sets (Life Techologies) used for validation of gene expression at AROS Applied Biotechnology A/S.

Additional file 5: Table S5. (A) Comparison of samples from day 0 to 3 versus control. (B) Comparison of samples from week 1 to 2 versus control. C) Comparison of samples from week 3 to 4 versus control. (D) Comparison of samples from the declining disease phase versus control.

Additional file 6: Figure S6. Validation of selected genes by qPCR showing correlation between the microarray data (X-axis, log2-transformed values) and the $\mathrm{qPCR}$ data (Y-axis, $\delta C t$ values). $\delta C_{t, \text { gene }}$ is calculated as $C_{t}$,

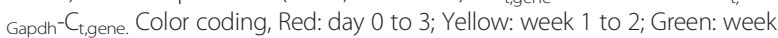
3 to 4; Blue: declining disease phase; Black: control.

Additional file 7: Figure S7. Validation of selected genes by qPCR showing a non-significant correlation between the microarray data (X-axis, log2 transformed values) and the qPCR data (Y-axis, $\delta C t$ values). $\delta C_{t, g e n e}$ is calculated as $C_{t, G a p d h}-C_{t, g e n e}$. Color coding, Red: day 0 to 3 ; Yellow: week 1 to 2; Green: week 3 to 4; Blue: declining disease phase; Black: control. 
Additional file 8: Table S8. Correlation data and $P$-values for correlation between microarray and qPCR data.

Additional file 9: Table S9. Selected Bio Functions related to bone. The Bio Functions that form the basis of the list of genes encoding proteins with a function in bone remodelling.

Additional file 10: Table S10. List of genes encoding proteins with a suggested function in bone remodelling. The list was created from data in the selected Bio Functions and supplemented with genes based on literature search. The data are also compared to data from other gene expression studies. A list of references is available (please contact the corresponding author).

\section{Abbreviations}

AIA: antibody-induced arthritis; AS: ankylosing spondylitis; BMP: bone morphogenetic protein; CFA: complete Freund's adjuvant; CIA: collagen-induced arthritis; Cll: collagen type II; ECM: extracellular matrix; ERK: extracellular signal-regulated kinases; FSH: follicle-stimulating hormone; GWAS: genome-wide association studies; IFA: incomplete Freund's adjuvant; IGF: insulin-like growth factor; IPA: Ingenuity Pathway Analysis; MMP: matrix metallopeptidase; OA: osteoarthritis; OB: osteoblast; OC: osteoclast; PGIA: proteoglycan-induced arthritis; PSA: psoriatic arthritis; RA: rheumatoid arthritis; TGF $\beta$ : transforming growth factor beta; TNFa: tumor necrosis factor alpha; WNT: wingless-type.

\section{Competing interests}

The authors declare that they have no competing interests.

\section{Authors' contributions}

KD conceived, designed and conducted the study, carried out the microscopic analysis with KM and further analysis of the array data with TLi, and drafted the manuscript. TLi analysed and interpreted the microarray data, the IPA, and assisted in drafting the manuscript. TM carried out the first-line analysis and interpretation of the microarray data, and revised the manuscript critically. KM analysed and interpreted the microscopic data, and revised the manuscript critically. LS conceived and participated in design of the study, and revised the manuscript critically. TLa conceived and participated in design of the study, and revised the manuscript critically. $\AA$ A conceived and participated in design of the study, and assisted substantially in drafting the manuscript. All authors read and approved the final manuscript, and agree to be accountable for all aspects of the work.

\section{Acknowledgements}

We wish to thank Rikke Bøgebo and Mikala Skydsgaard for assistance with data analysis, Marianne Løvendorf for technical assistance, John Zibert and Gunnar Olsen for contributing to the design of the study.

The study was supported by: The Danish Association for Rheumatism, The Graduate Program for In vivo Pharmacology, University of Copenhagen and LEO Pharma.

Received: 1 April 2014 Accepted: 19 January 2015

Published online: 05 March 2015

\section{References}

1. Finzel S, Englbrecht M, Engelke K, Stach C, Schett G. A comparative study of periarticular bone lesions in rheumatoid arthritis and psoriatic arthritis. Ann Rheum Dis. 2011;70:122-7.

2. Holmdahl R, Andersson EC, Andersen CB, Svejgaard A, Fugger L. Transgenic mouse models of rheumatoid arthritis. Immunol Rev. 1999;169:161-73.

3. Schett G, Stolina M, Dwyer D, Zack D, Uderhardt S, Kronke G, et al. Tumor necrosis factor alpha and RANKL blockade cannot halt bony spur formation in experimental inflammatory arthritis. Arthritis Rheum. 2009;60:2644-54.

4. Wozney JM, Rosen V. Bone morphogenetic protein and bone morphogenetic protein gene family in bone formation and repair. Clin Orthop Relat Res. 1998;346:26-37.

5. Schett G, Zwerina J, David JP. The role of Wnt proteins in arthritis. Nat Clin Pract Rheumatol. 2008:4:473-80.

6. Edgar R, Domrachev M, Lash AE. Gene Expression Omnibus: NCBI gene expression and hybridization array data repository. Nucleic Acids Res. 2002;30:207-10.
7. Aidinis V, Carninci P, Armaka M, Witke W, Harokopos V, Pavelka N, et al. Cytoskeletal rearrangements in synovial fibroblasts as a novel pathophysiological determinant of modeled rheumatoid arthritis. PLoS Genet. 2005;1:e48.

8. Haynes KR, Pettit AR, Duan R, Tseng HW, Glant TT, Brown MA, et al. Excessive bone formation in a mouse model of ankylosing spondylitis is associated with decreases in Wnt pathway inhibitors. Arthritis Res Ther. 2012;14:R253.

9. Lean JM, Murphy C, Fuller K, Chambers TJ. CCL9/MIP-1gamma and its receptor CCR1 are the major chemokine ligand/receptor species expressed by osteoclasts. J Cell Biochem. 2002;87:386-93.

10. Ota K, Quint P, Weivoda MM, Ruan M, Pederson L, Westendorf JJ, et al. Transforming growth factor beta 1 induces CXCL16 and leukemia inhibitory factor expression in osteoclasts to modulate migration of osteoblast progenitors. Bone. 2013;57:68-75.

11. Wu H, Xu G, Li YP. Atp6rod2 is an essential component of the osteoclastspecific proton pump that mediates extracellular acidification in bone resorption. J Bone Miner Res. 2009;24:871-85.

12. Zou W, Reeve JL, Liu Y, Teitelbaum SL, Ross FP. DAP12 couples c-Fms activation to the osteoclast cytoskeleton by recruitment of Syk. Mol Cell. 2008;31:422-31.

13. Eyre DR, Weis MA. Bone collagen: new clues to its mineralization mechanism from recessive osteogenesis imperfecta. Calcif Tissue Int. 2013;93:338-47.

14. Merle B, Garnero P. The multiple facets of periostin in bone metabolism. Osteoporos Int. 2012;23:1199-212.

15. Boskey AL, Christensen B, Taleb H, Sorensen ES. Post-translational modification of osteopontin: effects on in vitro hydroxyapatite formation and growth. Biochem Biophys Res Commun. 2012;419:333-8.

16. Gopalakrishnan R, Ouyang H, Somerman MJ, McCauley LK, Franceschi RT. Matrix gamma-carboxyglutamic acid protein is a key regulator of PTH-mediated inhibition of mineralization in MC3T3-E1 osteoblast-like cells. Endocrinology. 2001;142:4379-88.

17. Kaback LA, Soung DY, Naik A, Smith N, Schwarz EM, O'Keefe RJ, et al. Osterix/Sp7 regulates mesenchymal stem cell mediated endochondral ossification. J Cell Physiol. 2008;214:173-82.

18. Mackenzie NC, Zhu D, Milne EM, Van 't Hof R, Martin A, Darryl QL, et al. Altered bone development and an increase in FGF-23 expression in Enpp1(-/-) mice. PLoS One. 2012;7:e32177.

19. Moffatt P, Gaumond MH, Salois P, Sellin K, Bessette MC, Godin E, et al. Bril: a novel bone-specific modulator of mineralization. J Bone Miner Res. 2008;23:1497-508.

20. Nahar NN, Missana LR, Garimella R, Tague SE, Anderson HC. Matrix vesicles are carriers of bone morphogenetic proteins (BMPs), vascular endothelial growth factor (VEGF), and noncollagenous matrix proteins. J Bone Miner Metab. 2008;26:514-9.

21. Delany AM, Hankenson KD. Thrombospondin-2 and SPARC/osteonectin are critical regulators of bone remodeling. J Cell Commun Signal. 2009;3:227-38.

22. Chen XD, Shi S, Xu T, Robey PG, Young MF. Age-related osteoporosis in biglycan-deficient mice is related to defects in bone marrow stromal cells. J Bone Miner Res. 2002;17:331-40.

23. Ge G, Seo NS, Liang X, Hopkins DR, Hook M, Greenspan DS. Bone morphogenetic protein-1/tolloid-related metalloproteinases process osteoglycin and enhance its ability to regulate collagen fibrillogenesis. J Biol Chem. 2004;279:41626-33.

24. Izu Y, Sun M, Zwolanek D, Veit G, Williams V, Cha B, et al. Type XII collagen regulates osteoblast polarity and communication during bone formation. J Cell Biol. 2011;193:1115-30.

25. Kimura H, Kwan KM, Zhang Z, Deng JM, Darnay BG, Behringer RR, et al. Cthrc1 is a positive regulator of osteoblastic bone formation. PLoS One. 2008;3:e3174.

26. Raouf A, Ganss B, McMahon C, Vary C, Roughley PJ, Seth A. Lumican is a major proteoglycan component of the bone matrix. Matrix Biol. 2002;21:361-7.

27. Urano T, Narusawa K, Shiraki M, Sasaki N, Hosoi T, Ouchi Y, et al. Singlenucleotide polymorphism in the hyaluronan and proteoglycan link protein 1 (HAPLN1) gene is associated with spinal osteophyte formation and disc degeneration in Japanese women. Eur Spine J. 2011;20:572-7.

28. Gowen M, Lazner F, Dodds R, Kapadia R, Feild J, Tavaria M, et al. Cathepsin $\mathrm{K}$ knockout mice develop osteopetrosis due to a deficit in matrix degradation but not demineralization. J Bone Miner Res. 1999;14:1654-63. 
29. Baumgrass R, Williamson MK, Price PA. Identification of peptide fragments generated by digestion of bovine and human osteocalcin with the lysosomal proteinases cathepsin B, D, L, H, and S. J Bone Miner Res. 1997;12:447-55.

30. Lin Z, Bei JX, Shen M, Li Q, Liao Z, Zhang Y, et al. A genome-wide association study in Han Chinese identifies new susceptibility loci for ankylosing spondylitis. Nat Genet. 2012;44:73-7.

31. Ehlen HW, Chinenkova M, Moser M, Munter HM, Krause Y, Gross S, et al. Inactivation of anoctamin-6/Tmem16f, a regulator of phosphatidylserine scrambling in osteoblasts, leads to decreased mineral deposition in skeletal tissues. J Bone Miner Res. 2013;28:246-59.

32. Reveille JD, Sims AM, Danoy P, Evans DM, Leo P, Pointon JJ, et al. Genomewide association study of ankylosing spondylitis identifies non-MHC susceptibility loci. Nat Genet. 2010;42:123-7.

33. The Wellcome Trust Case Control Consortium. Genome-wide association study of 14,000 cases of seven common diseases and 3,000 shared controls. Nature. 2007:447:661-78.

34. Manchado E, Eguren M, Malumbres M. The anaphase-promoting complex/ cyclosome (APC/C): cell-cycle-dependent and -independent functions. Biochem Soc Trans. 2010;38:65-71.

35. Cui J, Stahl EA, Saevarsdottir S, Miceli C, Diogo D, Trynka G, et al. Genomewide association study and gene expression analysis identifies CD84 as a predictor of response to etanercept therapy in rheumatoid arthritis. PLoS Genet. 2013;9:e1003394.

36. Itoh S, Udagawa N, Takahashi N, Yoshitake F, Narita H, Ebisu S, et al. A critical role for interleukin-6 family-mediated Stat3 activation in osteoblast differentiation and bone formation. Bone. 2006:39:505-12.

37. Cobb JE, Plant D, Flynn E, Tadjeddine M, Dieude P, Cornelis F, et al. Identification of the tyrosine-protein phosphatase non-receptor type 2 as a rheumatoid arthritis susceptibility locus in Europeans. PLoS One. 2013;8:e66456.

38. Okada Y, Terao C, Ikari K, Kochi Y, Ohmura K, Suzuki A, et al. Meta-analysis identifies nine new loci associated with rheumatoid arthritis in the Japanese population. Nat Genet. 2012;44:511-6.

39. Raychaudhuri S, Remmers EF, Lee AT, Hackett R, Guiducci C, Burtt NP, et al. Common variants at CD40 and other loci confer risk of rheumatoid arthritis. Nat Genet. 2008:40:1216-23.

40. Zeggini E, Panoutsopoulou K, Southam L, Rayner NW, Day-Williams AG, Lopes MC, et al. Identification of new susceptibility loci for osteoarthritis (arCOGEN): a genome-wide association study. Lancet. 2012;380:815-23.

41. Valdes AM, Loughlin J, Timms KM, van Meurs JJ, Southam L, Wilson SG, et al. Genome-wide association scan identifies a prostaglandinendoperoxide synthase 2 variant involved in risk of knee osteoarthritis. Am J Hum Genet. 2008:82:1231-40.

42. Baraliakos X, Listing J, Rudwaleit M, Sieper J, Braun J. The relationship between inflammation and new bone formation in patients with ankylosing spondylitis 2. Arthritis Res Ther. 2008;10:R104

43. van der Heijde D, Landewe R, Einstein S, Ory P, Vosse D, Ni L, et al. Radiographic progression of ankylosing spondylitis after up to two years of treatment with etanercept. Arthritis Rheum. 2008;58:1324-31.

44. Filippin LI, Teixeira VN, Viacava PR, Lora PS, Xavier LL, Xavier RM. Temporal development of muscle atrophy in murine model of arthritis is related to disease severity. J Cachexia Sarcopenia Muscle. 2013;4:231-8.

45. Ortega N, Behonick D, Stickens D, Werb Z. How proteases regulate bone morphogenesis. Ann N Y Acad Sci. 2003:995:109-16.

46. Stickens D, Behonick DJ, Ortega N, Heyer B, Hartenstein B, Yu Y, et al. Altered endochondral bone development in matrix metalloproteinase 13-deficient mice. Development. 2004;131:5883-95.

47. Neve A, Corrado A, Cantatore FP. Osteoblast physiology in normal and pathological conditions. Cell Tissue Res. 2011;343:289-302.

48. Phang D, Rehage M, Bonafede B, Hou D, Xing W, Mohan S, et al. Inactivation of insulin-like-growth factors diminished the anabolic effects of pregnancy-associated plasma protein-A (PAPP-A) on bone in mice. Growth Horm IGF Res. 2010;20:192-200.

49. Qin X, Wergedal JE, Rehage M, Tran K, Newton J, Lam P, et al. Pregnancyassociated plasma protein-A increases osteoblast proliferation in vitro and bone formation in vivo. Endocrinology. 2006;147:5653-61.

50. Boldt HB, Conover CA. Pregnancy-associated plasma protein-A (PAPP-A): a local regulator of IGF bioavailability through cleavage of IGFBPs. Growth Horm IGF Res. 2007;17:10-8.
51. Conover CA, Chen BK, Resch ZT. Regulation of pregnancy-associated plasma protein-A expression in cultured human osteoblasts. Bone. 2004;34:297-302.

52. Sangiorgi G, Mauriello A, Bonanno E, Oxvig C, Conover CA, Christiansen M, et al. Pregnancy-associated plasma protein-a is markedly expressed by monocyte-macrophage cells in vulnerable and ruptured carotid atherosclerotic plaques: a link between inflammation and cerebrovascular events. J Am Coll Cardiol. 2006:47:2201-11.

53. Li W, Li H, Gu F. CRP and TNF-alpha induce PAPP-A expression in human peripheral blood mononuclear cells. Mediators Inflamm. 2012;2012:697832.

54. Miller BS, Bronk JT, Nishiyama T, Yamagiwa H, Srivastava A, Bolander ME, et al. Pregnancy associated plasma protein-A is necessary for expeditious fracture healing in mice. J Endocrinol. 2007;192:505-13.

55. Tanner SJ, Hefferan TE, Rosen CJ, Conover CA. Impact of pregnancyassociated plasma protein-a deletion on the adult murine skeleton. J Bone Miner Res. 2008;23:655-62.

56. Zhu S, Barbe MF, Liu C, Hadjiargyrou M, Popoff SN, Rani S, et al. Periostin-likefactor in osteogenesis. J Cell Physiol. 2009;218:584-92.

57. Sanchez-Sabate E, Alvarez L, Gil-Garay E, Munuera L, Vilaboa N. Identification of differentially expressed genes in trabecular bone from the iliac crest of osteoarthritic patients. Osteoarthritis Cartilage. 2009;17:1106-14.

58. Grgurevic L, Macek B, Mercep M, Jelic M, Smoljanovic T, Erjavec I, et al. Bone morphogenetic protein (BMP)1-3 enhances bone repair. Biochem Biophys Res Commun. 2011;408:25-31.

59. Lories RJ, Derese I, Ceuppens JL, Luyten FP. Bone morphogenetic proteins 2 and 6, expressed in arthritic synovium, are regulated by proinflammatory cytokines and differentially modulate fibroblast-like synoviocyte apoptosis. Arthritis Rheum. 2003:48:2807-18.

60. Marinova-Mutafchieva L, Taylor P, Funa K, Maini RN, Zvaifler NJ. Mesenchymal cells expressing bone morphogenetic protein receptors are present in the rheumatoid arthritis joint. Arthritis Rheum. 2000;43:2046-55.

61. Perrien DS, Nicks KM, Liu L, Akel NS, Bacon AW, Skinner RA, et al. Inhibin A enhances bone formation during distraction osteogenesis. J Orthop Res. 2012;30:288-95.

62. El-Gendi SS, Moniem AE, Tawfik NM, Ashmawy MM, Mohammed OA, Mostafa AK, et al. Value of serum and synovial fluid activin A and inhibin A in some rheumatic diseases. Int J Rheum Dis. 2010;13:273-9.

63. Chen D, Li Y, Zhou Z, Xing Y, Zhong Y, Zou X, et al. Synergistic inhibition of Wnt pathway by HIF-1alpha and osteoblast-specific transcription factor osterix (Osx) in osteoblasts. PLoS One. 2012;7:e52948.

\section{Submit your next manuscript to BioMed Central and take full advantage of:}

- Convenient online submission

- Thorough peer review

- No space constraints or color figure charges

- Immediate publication on acceptance

- Inclusion in PubMed, CAS, Scopus and Google Scholar

- Research which is freely available for redistribution 